\title{
The Importance of Hydration for Inhibiting Ice Recrystallization with $C$-Linked Antifreeze Glycoproteins.
}

\author{
Pawel Czechura, Roger Y. Tam, Elena Dimitrijevic, Anastasia Murphy \\ and Robert N. Ben* \\ University of Ottawa, Department of Chemistry, D'Iorio Hall, 10 Marie Curie, Ottawa, \\ ON, Canada, K1N 6N5 \\ * $\underline{\text { Rben@uottawa.ca }}$
}

\section{Supporting Information}

Part A

I. Synthesis of $C$-Linked Antifreeze Glycoprotein Analogues (1-4)

(i) General Experimental ....................... S2

(ii) Synthesis of Carbohydrate Component.............. S3

(iii) Synthesis of $C$-linked Glycoconjugate.............. S11

(iv) Solid Phase Synthesis of C-Linked Glycopeptides... S17

II. Assessing Antifreeze Activity.............................. S19

III. Conformational Analysis via Circular Dichroism................. S19

Part B

IV. NMR Spectra.................................... S21 


\section{(i) General Experimental}

All anhydrous reactions were performed in flame-dried or oven-dried glassware under a positive pressure of dry argon or nitrogen. Air or moisture-sensitive reagents and anhydrous solvents were transferred with oven-dried syringes or cannulae. All flash chromatography was performed with E. Merck silica gel 60 (230-400 mesh). All solution phase reactions were monitored using analytical thin layer chromatography (TLC) with $0.2 \mathrm{~mm}$ pre-coated silica gel aluminum plates 60 F254 (E. Merck). Components were visualized by illumination with a short-wavelength $(254 \mathrm{~nm})$ ultraviolet light and/or staining (ceric ammonium molybdate, potassium permanganate, or phosphomolybdate stain solution). All solvents used for anhydrous reactions were distilled. Tetrahydrofuran (THF) and diethyl ether were distilled from sodium/benzophenone under nitrogen. Dichloromethane, acetonitrile, triethylamine, benzene and diisopropylethylamine (DIPEA) were distilled from calcium hydride. Methanol was distilled from calcium sulfate. $N, N$-dimethylformamide (DMF) was stored over activated molecular sieves $4 \AA$ under argon.

${ }^{1} \mathrm{H}(300,360,400$, or $500 \mathrm{MHz})$ and ${ }^{13} \mathrm{C}$ NMR $(75,90,100$ or $125 \mathrm{MHz})$ spectra were recorded at ambient temperature on a Bruker Avance 300, Bruker AM 360, Bruker Avance 400 or Bruker Avance 500 spectrometer. Deuterated chloroform $\left(\mathrm{CDCl}_{3}\right)$, methanol $\left(\mathrm{CD}_{3} \mathrm{OD}\right)$, or water $\left(\mathrm{D}_{2} \mathrm{O}\right)$ were used as NMR solvents, unless otherwise stated. Chemical shifts are reported in ppm downfield from TMS and corrected using the solvent residual peak or TMS as an internal standard. Splitting patterns are designated as follows: $\mathrm{s}$, singlet; d, doublet; $\mathrm{t}$, triplet; q, quartet; $\mathrm{m}$, multiplet and br, broad. Low resolution mass spectrometry (LRMS) was performed on a Micromass Quatro-LC Electrospray spectrometer with a pump rate of $20 \mu \mathrm{L} / \mathrm{min}$ using electrospray ionization (ESI) or a Voyager DE-Pro matrix-assisted desorption ionization-time of flight (MALDI-TOF), (Applied Biosystem, Foster City, CA) mass spectrometer operated in the reflectron/positive-ion mode with DHB in $20 \% \mathrm{EtOH} / \mathrm{H}_{2} \mathrm{O}$ as the MALDI matrix. High resolution mass spectrometry (HRMS) data was acquired on Applied Biosystems/Sciex QStar (Concord, ON). Samples in $\mathrm{CH}_{2} \mathrm{Cl}_{2} / \mathrm{MeOH}$ 1:1 were mixed with Agilent ES tuning mix for internal calibration, and infused into the mass spectrometer at 5 $\mu \mathrm{L} / \mathrm{min}$. Infrared absorption spectra (IR) were recorded on a Shimadzu FTIR-8400S spectrometer as a neat film from $4000 \mathrm{~cm}^{-1}$ to $650 \mathrm{~cm}^{-1}$. Analytical and preparatory scale RP-HPLC were carried out with C-18 columns on a Varian Dynomax HPLC system equipped with a variable wavelength detector (ProStar 330 PDA) or a Waters Delta 600E HPLC system equipped with a variable wavelength detector. Automated solid phase peptide synthesis (SPPS) was performed on APEX 396 (Advanced ChemTech) equipped with a 40 well reaction vessel. 


\section{$\underline{\text { Scheme } 1}$}

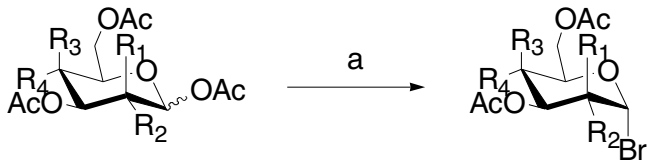

5a: Gal: $R_{1}, R_{4}=H ; R_{2}, R_{3}=O A c$
5b: Glc: $R_{1}, R_{3}=H ; R_{2}, R_{4}=O A c$
5c: Man: $R_{1}, R_{4}=O A c ; R_{2}, R_{3}=H$

6a: Gal $89 \%$

6b: Glc $94 \%$

6c: Man $92 \%$

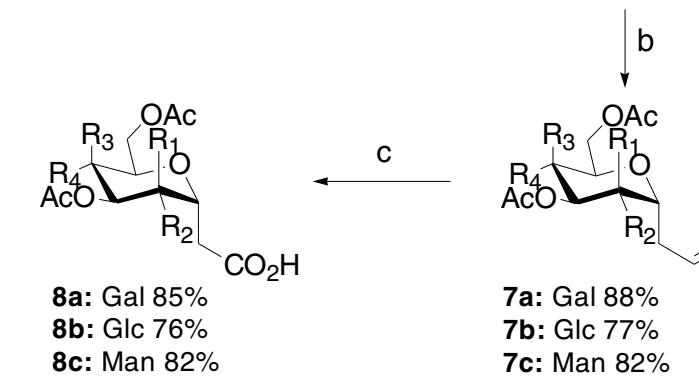

Conditions: (a) $\mathrm{HBr} / \mathrm{HOAc}$; (b) ( $\left.{ }^{\mathrm{n} B u}\right)_{6} \mathrm{Sn}_{2}$, allylphenylsulfone, benzene, hv; (c)

$\mathrm{RuCl}_{3} \cdot \mathrm{H}_{2} \mathrm{O}, \mathrm{NaIO}_{4}, \mathrm{CCl}_{4} / \mathrm{CH}_{3} \mathrm{CN} / \mathrm{H}_{2} \mathrm{O}$

\section{General protocol for Bromination of D-galactose pentaacetate, D-glucose pentaacetate and D-mannose pentaacetate}

To commercially available D-pyranose pentaacetate $(5 \mathrm{~g}, 12.81 \mathrm{mmol}), 30 \mathrm{~mL}$ of $\mathrm{HBr}$ in $\mathrm{AcOH}$ (33\% solution) was added at room temperature. The reaction was stirred for 40 minutes and then diluted with $\mathrm{CH}_{2} \mathrm{Cl}_{2}$. The solution was transferred to a separatory funnel containing ice and the organic layer was washed with ice water until neutral $\mathrm{pH}$. The organic extract was dried over $\mathrm{MgSO}_{4}$, filtered and concentrated to afford product in $\sim 90 \%$ yield. The crude product was crystallized from diethyl ether to form a white powder.

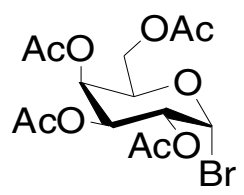

\section{2,3,4,6-tetra-O-acetyl- $\alpha$-D-galactopyranosyl bromide (6a)}

${ }^{1} \mathrm{H}$ NMR $\left(360 \mathrm{MHz}, \mathrm{CDCl}_{3}\right) \delta 6.56(1 \mathrm{H}, \mathrm{d}, J=3.9 \mathrm{~Hz}), 5.39(1 \mathrm{H}, \mathrm{m}), 5.22(1 \mathrm{H}, \mathrm{dd}, J=4.2$, $8.2 \mathrm{~Hz}), 4.85(1 \mathrm{H}, \mathrm{d}, J=4.3 \mathrm{~Hz}), 4.82(1 \mathrm{H}, \mathrm{d}, J=4.2 \mathrm{~Hz}), 4.25(1 \mathrm{H}, \mathrm{m}), 3.97(2 \mathrm{H}, \mathrm{m}), 1.98$ $(3 \mathrm{H}, \mathrm{s}), 1.98(3 \mathrm{H}, \mathrm{s}), 1.87(3 \mathrm{H}, \mathrm{s}), 1.82(3 \mathrm{H}, \mathrm{s}) ;{ }^{13} \mathrm{C} \mathrm{NMR}\left(90 \mathrm{MHz}, \mathrm{CDCl}_{3}\right) \delta 169.98$, 169.70, 169.64, 169.42, 88.19, 70.94, 67.73, 67.51, 66.78, 60.67, 20.47, 20.37, 20.31; LRMS (ESI): Calcd for $\mathrm{C}_{14} \mathrm{H}_{23} \mathrm{BrNO}_{9}\left[\mathrm{M}+\mathrm{NH}_{4}\right]^{+} 429.2$, found 429.9 . 


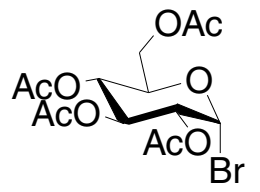

\section{2,3,4,6-tetra-O-acetyl- $\alpha$-D-glucopyranosyl bromide (6b)}

${ }^{1} \mathrm{H}$ NMR $\left(300 \mathrm{MHz}, \mathrm{CDCl}_{3}\right) \delta 6.16(1 \mathrm{H}, \mathrm{d}, J=1.3 \mathrm{~Hz}), 5.53(1 \mathrm{H}, \mathrm{dd}, J=3.6,7.8 \mathrm{~Hz}), 5.27$ $(2 \mathrm{H}, \mathrm{m}), 4.15(1 \mathrm{H}, \mathrm{dd}, J=9.6,18 \mathrm{~Hz}), 4.07(1 \mathrm{H}, \mathrm{m}), 3.98(1 \mathrm{H}, \mathrm{dd}, J=2.1,12 \mathrm{~Hz}), 2.01$, $(3 \mathrm{H}, \mathrm{s}), 1.98(3 \mathrm{H}, \mathrm{s}), 1.91(3 \mathrm{H}, \mathrm{s}), 1.84(3 \mathrm{H}, \mathrm{s}) ;{ }^{13} \mathrm{C} \mathrm{NMR}\left(75 \mathrm{MHz}, \mathrm{CDCl}_{3}\right) \delta 170.28$, 169.51, 169.39, 169.35, 83.20, 72.71, 71.90, 67.78, 65.05, 61.27, 20.60, 20.49, 20.41; LRMS (ESI): Calcd for $\mathrm{C}_{14} \mathrm{H}_{23} \mathrm{BrNO}_{9}\left[\mathrm{M}+\mathrm{NH}_{4}\right]^{+} 429.2$, found 429.9 .

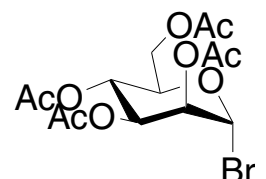

\section{2,3,4,6-tetra-O-acetyl-a-D-mannopyranosyl bromide (6c)}

${ }^{1} \mathrm{H}$ NMR $\left(360 \mathrm{MHz}, \mathrm{CDCl}_{3}\right) \delta 6.45(1 \mathrm{H}, \mathrm{d}, J=3.9 \mathrm{~Hz}), 5.39(1 \mathrm{H}, \mathrm{dd}, J=9.6,10 \mathrm{~Hz}), 5.01$ $(1 \mathrm{H}, \mathrm{dd}, J=9.6,9.9 \mathrm{~Hz}), 4.67,(1 \mathrm{H}, \mathrm{ddd}, J=1.5,3.9,5.4 \mathrm{~Hz}), 4.16(2 \mathrm{H}, \mathrm{m}), 3.95(1 \mathrm{H}, \mathrm{d}$, $J=12.0 \mathrm{~Hz}), 1.92(3 \mathrm{H}, \mathrm{s}), 1.91(3 \mathrm{H}, \mathrm{s}), 1.91(3 \mathrm{H}, \mathrm{s}), 1.90(3 \mathrm{H}, \mathrm{s}) ;{ }^{13} \mathrm{C}$ NMR $(90 \mathrm{MHz}$, $\left.\mathrm{CDCl}_{3}\right) \delta 169.98,169.70,169.64,169.42,88.19,70.94,76.73,67.57,66.78,60.67,20.47$, 20.37, 20.31; LRMS (ESI): Calcd for $\mathrm{C}_{14} \mathrm{H}_{23} \mathrm{BrNO}_{9}\left[\mathrm{M}+\mathrm{NH}_{4}\right]^{+} 429.2$, found 429.9 .

\section{General protocol for photochemical allylation of 2,3,4,6-tetra-O-acetyl- $\alpha$-D- galactopyranosyl bromide, 2,3,4,6-tetra-O-acetyl- $\alpha$-D-glucopyranosyl bromide, 2,3,4,6-tetra-O-acetyl- $\alpha$-D-mannopyranosyl bromide ${ }^{1}$}

To a solution of 2,3,4,6-tetra-O-acetyl- $\alpha$-D-pyranosyl bromide $(1.24 \mathrm{~g}, 3.01 \mathrm{mmol})$ in benzene $(15 \mathrm{~mL})$, allyl phenyl sulfone $(1.418 \mathrm{~mL}, 7.52 \mathrm{mmol})$, and bis-tributyl tin $(2.19$ $\mathrm{mL}, 4.21 \mathrm{mmol}$ ) were added. The solution was degassed and sonicated for 30 minutes under argon atmosphere; the sealed flask was irradiated for 9 hours under a $450 \mathrm{~W}$ mercury arc lamp. The reaction was monitored using TLC at time intervals of 2, 6 and 8 hours. The reaction mixture was loaded directly onto a silica gel column packed with hexanes. The organostannanes were flushed with 3 void volumes of hexanes, after which the solvent system was changed to 5:1 hexanes/EtOAc to remove the unreacted allyl phenyl sulfone. The product was eluted with 3:1 hexanes/EtOAc and concentrated to afford the allylated derivative as colorless oil ( $\sim 95 \%$ yield).

\footnotetext{
${ }^{1}$ Pontén, F.; Magnusson, G. J. Org. Chem. 1996, 61, 7463.
} 


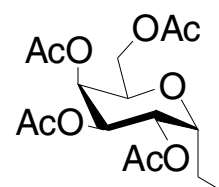

\section{Allyl 2,3,4,6-tetra-O-acetyl- $\alpha$-D-galactopyranoside (7a)}

${ }^{1} \mathrm{H}$ NMR $\left(360 \mathrm{MHz}, \mathrm{CDCl}_{3}\right) \delta 5.76(1 \mathrm{H}$, dddd, J=6.5, 7.1, 10.0, $16.6 \mathrm{~Hz}), 5.42(1 \mathrm{H}, \mathrm{dd}$, $\mathrm{J}=2.4,3.1 \mathrm{~Hz}), 5.28(1 \mathrm{H}, \mathrm{dd}, \mathrm{J}=4.8,9.3 \mathrm{~Hz}), 5.22(1 \mathrm{H}, \mathrm{dd}, \mathrm{J}=3.1,9.3 \mathrm{~Hz}), 5.13(1 \mathrm{H}, \mathrm{ddd}$, $\mathrm{J}=1.6,3.0,16.6 \mathrm{~Hz}), 5.12(1 \mathrm{H}, \mathrm{ddd}, \mathrm{J}=1.4,3.0,10.0 \mathrm{~Hz}), 4.30(1 \mathrm{H}, \mathrm{ddd}, \mathrm{J}=4.7,5.2,10.3$ $\mathrm{Hz}), 4.21(1 \mathrm{H}, \mathrm{dd}, \mathrm{J}=8.9,12.5 \mathrm{~Hz}), 4.09(2 \mathrm{H}, \mathrm{m}), 2.46(1 \mathrm{H}, \mathrm{m}), 2.29(1 \mathrm{H}, \mathrm{m}), 2.12(1 \mathrm{H}$, s), $2.07(1 \mathrm{H}, \mathrm{s}), 2.04(1 \mathrm{H}, \mathrm{s}), 2.03(1 \mathrm{H}, \mathrm{s}) ;{ }^{13} \mathrm{C} \mathrm{NMR}\left(90 \mathrm{MHz}, \mathrm{CDCl}_{3}\right) \delta 170.5,170.1$, 169.9, 169.8, 133.3, 117.6, 71.4, 68.2, 67.9, 61.4, 30.9, 20.8, 20.7, 20.6; LRMS (ESI): Calcd for $\mathrm{C}_{17} \mathrm{H}_{25} \mathrm{O}_{9}[\mathrm{M}+\mathrm{H}]^{+}$373.4, found 373.1.

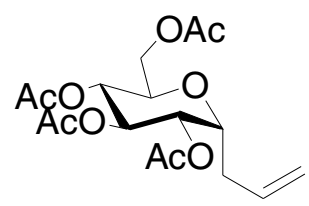

\section{Allyl 2,3,4,6-tetra-O-acetyl- $\alpha$-D-glucopyranoside (7b)}

The product was co-eluted with starting material with 3:1 hexanes to EtOAc and concentrated. The mixture was re-dissolved in a 1:1 mixture of acetone and water, to which silver carbonate was added. The reaction was allowed to stir for 30 minutes, after which it was filtered. The product was extracted with $\mathrm{CH}_{2} \mathrm{Cl}_{2}$, washed with water, brine, dried over $\mathrm{MgSO}_{4}$ and concentrated. The colorless oil was purified with flash column chromatography in 3:1 hexanes/EtOAc, and afforded $\mathbf{7 b}$ as a colorless oil in $\sim 70 \%$ yield over two steps.

${ }^{1} \mathrm{H}$ NMR $\left(360 \mathrm{MHz}, \mathrm{CDCl}_{3}\right) \delta 5.76(1 \mathrm{H}, \mathrm{dddd}, J=6.6,8.0,16.0 \mathrm{~Hz}), 5.41(1 \mathrm{H}, \mathrm{dd}, J=6.8$, $13.2 \mathrm{~Hz}), 5.18(2 \mathrm{H}, \mathrm{m}), 5.01(1 \mathrm{H}, \mathrm{dd}, J=6.5,12.1 \mathrm{~Hz}), 4.35(1 \mathrm{H}, \mathrm{m}), 4.23(1 \mathrm{H}, \mathrm{dd}, J=5.9$, $12.8 \mathrm{~Hz}), 4.10(1 \mathrm{H}, \mathrm{dd}, J=3.0,13.2 \mathrm{~Hz}), 3.89(1 \mathrm{H}, \mathrm{m}), 2.59(1 \mathrm{H}, \mathrm{m}), 2.38(1 \mathrm{H}, \mathrm{m}), 2.19$ $(3 \mathrm{H}, \mathrm{s}), 2.01(3 \mathrm{H}, \mathrm{s}), 1.95(3 \mathrm{H}, \mathrm{s}), 1.91(3 \mathrm{H}, \mathrm{s}) ;{ }^{13} \mathrm{C} \mathrm{NMR}\left(90 \mathrm{MHz}, \mathrm{CDCl}_{3}\right) \delta 177.30$, $174.48,170.58,169.55,169.43,168.66,163.66,140.11,115.29,76.97,76.61,69.31$, 68.76, 67.71, 67.47, 32.83, 26.55, 20.51, 20.48, 20.36, 20.22, 20.09, 20.06, 19.86; HRMS (ESI): Calcd for $\mathrm{C}_{17} \mathrm{H}_{25} \mathrm{O}_{9}[\mathrm{M}+\mathrm{H}]^{+} 373.1498$, found 373.1461 . 


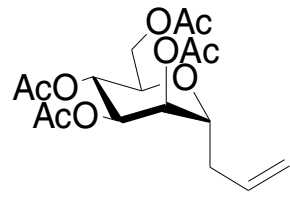

\section{Allyl 2,3,4,6-tetra-O-acetyl- $\alpha$-D-mannopyranoside (7c)}

${ }^{1} \mathrm{H}$ NMR $\left(360 \mathrm{MHz}, \mathrm{CDCl}_{3}\right) \delta 5.77(1 \mathrm{H}, \mathrm{dddd}, \mathrm{J}=6.8,10.0,10.4 \mathrm{~Hz}), 5.23(1 \mathrm{H}, \mathrm{dd}$, $\mathrm{J}=3.24,6.8 \mathrm{~Hz}), 5.15(1 \mathrm{H}, \mathrm{m}), 5.07(1 \mathrm{H}, \mathrm{m}), 4.29(1 \mathrm{H}, \mathrm{dd}, \mathrm{J}=6.4,12.2 \mathrm{~Hz}), 4.06(1 \mathrm{H}, \mathrm{dd}$, $\mathrm{J}=2.9,8.2 \mathrm{~Hz}), 4.03(1 \mathrm{H}, \mathrm{m}), 3.86(1 \mathrm{H}, \mathrm{ddd}, \mathrm{J}=2.9,6.8,8.6 \mathrm{~Hz}), 2.52(1 \mathrm{H}, \mathrm{m}), 2.29(1 \mathrm{H}$, m), $2.07(3 \mathrm{H}, \mathrm{s}), 2.02(3 \mathrm{H}, \mathrm{s}), 1.99(3 \mathrm{H}, \mathrm{s}), 1.94(3 \mathrm{H}, \mathrm{s}) ;{ }^{13} \mathrm{C} \mathrm{NMR}\left(90 \mathrm{MHz}, \mathrm{CDCl}_{3}\right) \delta$ $174.30,171.58,170.38,169.98,169.13,168.16,163.11,140.21,114.21,73.91,68.81$, 68.36, 67.69, 61.49, 35.81, 26.95, 22.53, 22.49, 22.31, 20.20, 20.01, 19.98, 19.45; LRMS (ESI): Calcd for $\mathrm{C}_{17} \mathrm{H}_{25} \mathrm{O}_{9}[\mathrm{M}+\mathrm{H}]^{+}$373.4, found 373.1.

\section{General protocol for oxidation of allyl 2,3,4,6-tetra-O-acetyl- $\alpha$-D-pyranoside to 2,3,4,6-tetra-O-acetyl- $\alpha$-D-pyranosyl acid}

Allylated pyranose tetraacetate $(0.83 \mathrm{~g}, 2.23 \mathrm{mmol})$ was dissolved in $14 \mathrm{~mL}$ of a solution of (2:2:3) acetonitrile: carbon tetrachloride: water, followed by the addition of sodium periodate $(1.90 \mathrm{~g} .8 .92 \mathrm{mmol})$. A catalytic amount of ruthenium trichloride trihydrate was then added, and the reaction was allowed to stir at room temperature for 2-3 hours. The solution was filtered through celite and transferred to a separatory funnel with dichlroromethane. The organic layer was washed successively with saturated ammonium chloride solution, saturated brine solution, dried over $\mathrm{MgSO}_{4}$, filtered and concentrated to afford the carboxylic acid derivative in $>75 \%$ yield.

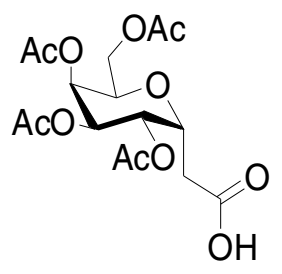

\section{2,3,4,6-tetra-O-acetyl-a-D-galactopyranosyl acid (8a)}

${ }^{1} \mathrm{H}$ NMR $\left(400 \mathrm{MHz}, \mathrm{CDCl}_{3}\right) \delta 5.43(1 \mathrm{H}, \mathrm{t}, J=2.8 \mathrm{~Hz}), 5.33(1 \mathrm{H}, \mathrm{dd}, J=8.9,5.0 \mathrm{~Hz}),$, $(1 \mathrm{H}, \mathrm{dd}, J=8.9,3.3 \mathrm{~Hz}), 4.70(1 \mathrm{H}$, ddd, $J=9.3,8.3,5.3 \mathrm{~Hz}), 4.30-4.08(3 \mathrm{H}, \mathrm{m}), 2.73(1 \mathrm{H}$, dd, $J=15.6,8.7 \mathrm{~Hz}), 2.63(1 \mathrm{H}, \mathrm{dd}, J=15.6,5.7 \mathrm{~Hz}), 2.13(3 \mathrm{H}, \mathrm{s}), 2.07(3 \mathrm{H}, \mathrm{s}), 2.04(6 \mathrm{H}$, s); ${ }^{13} \mathrm{C}$ NMR $\left(90 \mathrm{MHz}, \mathrm{CDCl}_{3}\right) \delta: 175.5,170.8,170.1,170.0,169.7,69.4,68.9,67.8$, 67.6, 67.1, 61.2, 33.15, 20.7; IR (thin film): 3706-2355, $1748 \mathrm{~cm}^{-1}$. 


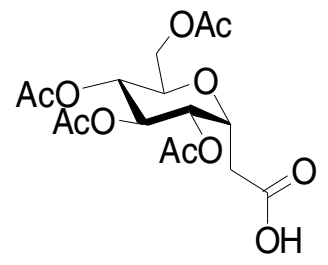

\section{2,3,4,6-tetra-O-acetyl- $\alpha-D$-glucopyranosyl acid (8b)}

${ }^{1} \mathrm{H}$ NMR $\left(360 \mathrm{MHz}, \mathrm{CDCl}_{3}\right) \delta 5.28(1 \mathrm{H}, \mathrm{ddd}, J=4.6,9.7 \mathrm{~Hz}), 5.17(1 \mathrm{H}, \mathrm{ddd}, J=6.7$, $9.9 \mathrm{~Hz}), 5.03(1 \mathrm{H}, \mathrm{q}, J=8.9 \mathrm{~Hz}), 4.84(1 \mathrm{H}, \mathrm{m}), 4.68(1 \mathrm{H}, \mathrm{m}), 4.26(1 \mathrm{H}, \mathrm{ddd}, J=6.2,9.9 \mathrm{~Hz})$, $4.06(1 \mathrm{H}, \mathrm{m}), 3.94(1 \mathrm{H}, \mathrm{m}), 3.86(1 \mathrm{H}, \mathrm{m}), 2.81(1 \mathrm{H}, \mathrm{m}), 2.04(3 \mathrm{H}, \mathrm{s}), 2.02(3 \mathrm{H}, \mathrm{s}), 2.00$ $(3 \mathrm{H}, \mathrm{s}), 1.99(3 \mathrm{H}, \mathrm{s}) ;{ }^{13} \mathrm{C} \mathrm{NMR}\left(90 \mathrm{MHz}, \mathrm{CDCl}_{3}\right) \delta 177.28,174.50,170.62,169.84$, $101.95,69.31,68.76,67.71,67.50,67.47,67.01,66.73,66.43,61.00,32.92,20.89,20.77$, 20.72, 20.67, 20.65, 20.60; HRMS (ESI): Calcd for $\mathrm{C}_{16} \mathrm{H}_{23} \mathrm{O}_{11}[\mathrm{M}+\mathrm{H}]^{+}$391.1240, found 391.1216 .

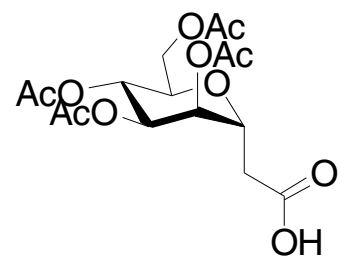

\section{2,3,4,6-tetra-O-acetyl-a-D-mannopyranosyl acid (8c)}

${ }^{1} \mathrm{H}$ NMR $\left(300 \mathrm{MHz}, \mathrm{CDCl}_{3}\right) \delta 5.33(1 \mathrm{H}, \mathrm{dd}, J=5.4,7.8 \mathrm{~Hz}), 5.14(1 \mathrm{H}, \mathrm{m}), 4.49(1 \mathrm{H}, \mathrm{m})$, $4.21(1 \mathrm{H}, \mathrm{dd} J=5.7,13.5 \mathrm{~Hz}), 4.01(1 \mathrm{H}, \mathrm{m}), 2.63(1 \mathrm{H}, \mathrm{ddd}, J=6.4,7.9,9.31 \mathrm{H}), 2.10(3 \mathrm{H}$, s), $1.99(3 \mathrm{H}, \mathrm{s}), 1.89(3 \mathrm{H}, \mathrm{s}), 1.75(3 \mathrm{H}, \mathrm{s}), 1.44(4 \mathrm{H}, \mathrm{m}) ;{ }^{13} \mathrm{C} \mathrm{NMR}\left(75 \mathrm{MHz}, \mathrm{CDCl}_{3}\right) \delta$ $174.53,171.15,170.30,170.10,169.99,133.96,116.38,73.19,68.81,68.34,67.63$, $63.13,61.79,35.76,35.13,26.93,24.79,21.17,21.09,21.06,20.56,19.23,14.22$; IR (thin film): $3300-2350,1750 \mathrm{~cm}^{-1}$; HRMS (ESI): Calcd for $\mathrm{C}_{16} \mathrm{H}_{23} \mathrm{O}_{11}[\mathrm{M}+\mathrm{H}]^{+} 391.1240$, found 391.1228 . 


\section{Scheme 2}

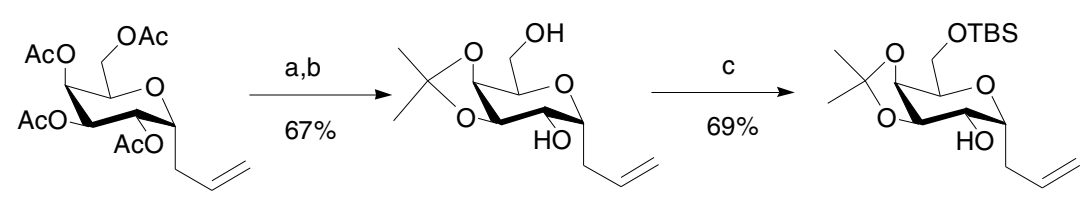

$7 a$

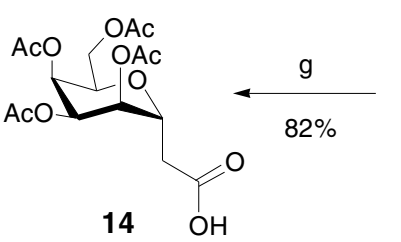

9

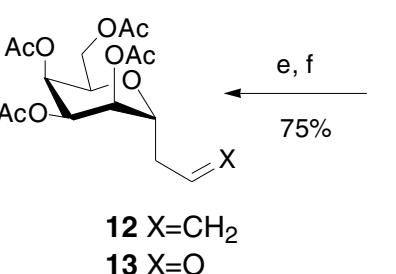

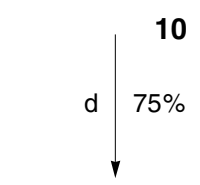

Conditions: (a) NaOMe, $\mathrm{MeOH}$; (b) $\left(\mathrm{CH}_{3}\right)_{2} \mathrm{C}\left(\mathrm{OCH}_{3}\right)_{2}, p-\mathrm{TsOH}, \mathrm{CH}_{3} \mathrm{CN}$; (c) TBDMSCI, DMAP, py;

(d) $(\mathrm{CO})_{2} \mathrm{Cl}_{2}$, DMSO, $\mathrm{Et}_{3} \mathrm{~N}$, then $\mathrm{NaBH}_{4}, \mathrm{CH}_{3} \mathrm{OH}$; (e) $80 \% \mathrm{HOAc}-\mathrm{H}_{2} \mathrm{O}$, then $\mathrm{Ac}_{2} \mathrm{O}$, py- $\mathrm{CH}_{2} \mathrm{Cl}_{2}$;

(f) $\mathrm{O}_{3}, \mathrm{PPh}_{3}, \mathrm{CH}_{2} \mathrm{Cl}_{2},-78{ }^{\circ} \mathrm{C}$; (g) $\mathrm{NaClO}_{2}, \mathrm{KH}_{2} \mathrm{PO}_{4}$, 2-methyl-2-butene, ${ }^{\mathrm{t}} \mathrm{BuOH}-{ }^{\mathrm{i}} \mathrm{PrOH}-\mathrm{H}_{2} \mathrm{O}$.

\section{3,4-O-isopropylidene-1-allyl- $\alpha$-D-galactopyranoside (9)}

To a solution of allylglycoside $(0.81 \mathrm{~g}, 3.97 \mathrm{mmol})$ and dimethoxypropane $(2.44 \mathrm{~mL}$, $19.85 \mathrm{mmol})$ in dry acetonitrile $(15 \mathrm{~mL}), \mathrm{p}-\mathrm{TsOH}(40 \mathrm{mg})$ was added and the reaction mixture was stirred for $2 \mathrm{~h}$. Water $(3 \mathrm{~mL})$ was then added and after 30 min the reaction was neutralized with triethylamine and evaporated. Flash column chromatography $(10 \%$ $\left.\mathrm{CH}_{2} \mathrm{Cl}_{2} / \mathrm{EtOAc}\right)$ afforded $9(0.69 \mathrm{~g}, 70 \%)$ as white crystalline solid.

${ }^{1} \mathrm{H}$ NMR (400 MHz, $\left.\mathrm{CDCl}_{3}\right) \delta 5.86(1 \mathrm{H}, \mathrm{dddd}, J=7.1,10.2,17.2 \mathrm{~Hz}), 5.15(1 \mathrm{H}$, dd, $J=1.8,17.2 \mathrm{~Hz}), 5.09$ (1H, dddd, $J=1.5,17.2 \mathrm{~Hz}), 4.33-4.25(2 \mathrm{H}, \mathrm{m}), 4.08-4.02(2 \mathrm{H}, \mathrm{m})$, 3.87-3.77 $(2 \mathrm{H}, \mathrm{m}), 2.45-2.30(2 \mathrm{H}, \mathrm{m}), 2.20(1 \mathrm{H}, \mathrm{dd}, J=3.2,9.3 \mathrm{~Hz}), 2.00(1 \mathrm{H}, \mathrm{d}, J=4.5$ $\mathrm{Hz}), 1.47(3 \mathrm{H}, \mathrm{s}), 1.32(3 \mathrm{H}, \mathrm{s}) ;{ }^{13} \mathrm{C} \mathrm{NMR}\left(100 \mathrm{MHz}, \mathrm{CDCl}_{3}\right) \delta 134.3,117.7,109.7,74.8$, 73.1, 70.6, 69.6, 69.1, 63.6, 34.9, 26.8, 24.6; HRMS (ESI): Calcd for $\mathrm{C}_{12} \mathrm{H}_{21} \mathrm{O}_{5}[\mathrm{M}+\mathrm{H}]^{+}$ 245.1388 , found 245.1377 . 


\section{3,4-O-isopropylidene-6-O-tert-butyldimethylsilyl-1-allyl-a-D-galactopyranoside} (10)

To a solution of diol $9(0.30 \mathrm{~g}, 1.21 \mathrm{mmol})$ in dry pyridine: $\mathrm{CH}_{2} \mathrm{Cl}_{2}(5: 5 \mathrm{~mL})$, tertbutyldimethylsilyl chloride $(0.22 \mathrm{~g}, 1.45 \mathrm{mmol})$ and DMAP $(7 \mathrm{mg})$ were added sequentially. The reaction mixture was stirred overnight, diluted with $\mathrm{CH}_{2} \mathrm{Cl}_{2}$ and washed successively with $0.5 \mathrm{~N} \mathrm{HCl}$, water and brine. The organic extract was dried over $\mathrm{MgSO}_{4}$ and concentrated in vacuo. Flash column chromatography (25\% EtOAc/hexanes) gave the product in quantitative yield $(0.43 \mathrm{~g},>99 \%)$.

${ }^{1} \mathrm{H}$ NMR $\left(400 \mathrm{MHz}, \mathrm{CDCl}_{3}\right) \delta 5.82(1 \mathrm{H}, \mathrm{dddd}, J=7.0,7.0,10.2,17.1 \mathrm{~Hz}), 5.16-5.10(1 \mathrm{H}$, m), 5.08-5.04 $(1 \mathrm{H}, \mathrm{m}), 4.34(1 \mathrm{H}, \mathrm{dd}, J=1.8,7.1 \mathrm{~Hz}), 4.17(1 \mathrm{H}, \mathrm{dd}, J=3.4,7.1 \mathrm{~Hz}), 3.99-$ $3.93(2 \mathrm{H}, \mathrm{m}), 3.76-3.64(3 \mathrm{H}, \mathrm{m}), 2.45(1 \mathrm{H}, \mathrm{br} \mathrm{s}), 2.35-2.28(2 \mathrm{H}, \mathrm{m}), 1.43(3 \mathrm{H}, \mathrm{s}), 1.28$ $(3 \mathrm{H}, \mathrm{s}), 0.84(9 \mathrm{H}, \mathrm{s}), 0.02(3 \mathrm{H}, \mathrm{s}), 0.02(3 \mathrm{H}, \mathrm{s}) ;{ }^{13} \mathrm{C} \mathrm{NMR}\left(100 \mathrm{MHz}, \mathrm{CDCl}_{3}\right) \delta 134.4$, 117.5, 109.0, 74.6, 71.7, 70.5, 70.0, 69.7, 62.6, 35.0, 27.0, 25.9, 24.5, -5.3 ,-5.4; HRMS (ESI): Calcd for $\mathrm{C}_{18} \mathrm{H}_{35} \mathrm{O}_{5} \mathrm{Si}[\mathrm{M}+\mathrm{H}]^{+} 359.2253$, found 359.2257.

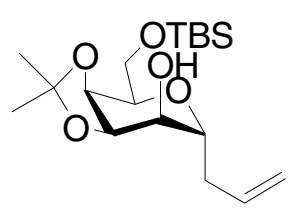

\section{3,4-O-isopropylidene-6-O-tert-butyldimethylsilyl-1-allyl- $\alpha$-D-talopyranoside (11)}

To a solution of oxalyl chloride $(0.13 \mathrm{~mL}, 1.51 \mathrm{mmol})$ in $\mathrm{CH}_{2} \mathrm{Cl}_{2}(10 \mathrm{~mL})$ at $-78{ }^{\circ} \mathrm{C}$, DMSO $(0.23 \mathrm{~mL}, 3.31 \mathrm{mmol})$ was added dropwise and the reaction mixture was stirred for $30 \mathrm{~min}$. Then, $10(0.27 \mathrm{~g}, 0.75 \mathrm{mmol})$ in $\mathrm{CH}_{2} \mathrm{Cl}_{2}(10 \mathrm{~mL})$ was added over $10 \mathrm{~min}$. After an additional $30 \mathrm{~min}$ of stirring, triethylamine $(0.73 \mathrm{~mL}, 5.27 \mathrm{mmol})$ was added at $60^{\circ} \mathrm{C}$ and the reaction mixture was brought to room temperature. After $1 \mathrm{~h}$, the reaction mixture was diluted with $\mathrm{CH}_{2} \mathrm{Cl}_{2}$ and water was added. The layers were separated and the organic extract was washed with water, brine, dried over $\mathrm{MgSO}_{4}$, and concentrated. The crude product was immediately dissolved in $\mathrm{MeOH}(20 \mathrm{~mL})$ and $\mathrm{NaBH}_{4}(0.06 \mathrm{~g}, 1.51$ mmol) was added. After stirring for $30 \mathrm{~min}$, the reaction mixture was quenched with acetic acid and the solvent was evaporated. The residue was taken up in $\mathrm{CH}_{2} \mathrm{Cl}_{2}$, washed with water, brine and then dried over $\mathrm{MgSO}_{4}$. The organic phase was concentrated in vacuo and after flash column chromatography (25\% EtOAc/hexanes), compound $\mathbf{1 1}$ was obtained as an oil $(0.41 \mathrm{~g}, 75 \%)$.

${ }^{1} \mathrm{H}$ NMR $\left(400 \mathrm{MHz}, \mathrm{CDCl}_{3}\right) \delta 5.93(1 \mathrm{H}$, dddd, $J=6.7,7.4,10.2,17.1 \mathrm{~Hz}), 5.19-5.07(2 \mathrm{H}$, $\mathrm{m}), 4.50(1 \mathrm{H}, \mathrm{dd}, J=3.6,8.0 \mathrm{~Hz}), 4.42(1 \mathrm{H}, \mathrm{dd}, J=1.5,8.0 \mathrm{~Hz}), 3.77(1 \mathrm{H}, \mathrm{ddd}, J=4.24$, 6.50, $9.65 \mathrm{~Hz}), 3.74-3.57(4 \mathrm{H}, \mathrm{m}), 2.52-2.27(2 \mathrm{H}, \mathrm{m}), 1.99(1 \mathrm{H}, \mathrm{br} \mathrm{s}), 1.51(3 \mathrm{H}, \mathrm{s}), 1.36$ $(3 \mathrm{H}, \mathrm{s}), 0.89(9 \mathrm{H}, \mathrm{s}), 0.06(3 \mathrm{H}, \mathrm{s}), 0.06(3 \mathrm{H}, \mathrm{s}) ;{ }^{13} \mathrm{C} \mathrm{NMR}\left(100 \mathrm{MHz}, \mathrm{CDCl}_{3}\right) \delta 134.4$, 
117.6, 109.8, 73.4, 73.1, 72.5, 70.5, 68.2, 62.3, 36.9, 26.2, 25.9, 24.7, -5.3, -5.5;

HRMS (ESI): Calcd for $\mathrm{C}_{18} \mathrm{H}_{38} \mathrm{NO}_{5} \mathrm{Si}\left[\mathrm{M}+\mathrm{NH}_{4}\right]^{+} 376.2519$, found 376.2508.

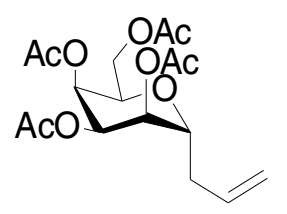

\section{Allyl 2,3,4,6-tetra-O-acetyl- $\alpha$-D-talopyranoside (12)}

A solution of acetal $11(0.22 \mathrm{~g}, 0.61 \mathrm{mmol})$ in $80 \%$ acetic acid $(20 \mathrm{~mL})$ was heated for $1 \mathrm{~h}$ at $80{ }^{\circ} \mathrm{C}$. The reaction mixture was cooled and the solvent was evaporated. The residue was taken up in pyridine $(20 \mathrm{~mL})$, followed by addition of acetic anhydride $(10 \mathrm{~mL})$ and DMAP $(10 \mathrm{mg})$. The reaction mixture was stirred overnight, then diluted with $\mathrm{CH}_{2} \mathrm{Cl}_{2}$ and washed successively with saturated $\mathrm{CuSO}_{4}$ solution, water and brine. The organic extract was dried over $\mathrm{MgSO}_{4}$ and concentrated. Flash column chromatography afforded compound 12 as a white crystalline solid $(0.17 \mathrm{~g}, 75 \%)$.

${ }^{1} \mathrm{H}$ NMR $\left(500 \mathrm{MHz}, \mathrm{CDCl}_{3}\right) \delta 5.77(1 \mathrm{H}$, dddd, $J=6.9,6.9,10.7,16.6 \mathrm{~Hz}), 5.44(1 \mathrm{H}, \mathrm{t}$, $J=3.2 \mathrm{~Hz}), 5.18(1 \mathrm{H}, \mathrm{dd}, J=3.2,5.1 \mathrm{~Hz}), 5.11-5.08(1 \mathrm{H}, \mathrm{m}), 5.08-5.06(1 \mathrm{H}, \mathrm{m}), 4.83(1 \mathrm{H}$, $\mathrm{dd}, J=3.2,7.3 \mathrm{~Hz}), 4.62(1 \mathrm{H}, \mathrm{dd}, J=8.9,12.1 \mathrm{~Hz}), 4.18(1 \mathrm{H}, \mathrm{ddd}, J=3.8,4.8,8.8 \mathrm{~Hz}), 4.09$ $(1 \mathrm{H}, \mathrm{dd}, J=3.6,12.2 \mathrm{~Hz}), 4.01(1 \mathrm{H}, \mathrm{ddd}, J=4.8,7.5,7.5 \mathrm{~Hz}), 2.39-2.23(2 \mathrm{H}, \mathrm{m}), 2.08(3 \mathrm{H}$, s), $2.05(3 \mathrm{H}, \mathrm{s}), 2.04(3 \mathrm{H}, \mathrm{s}), 2.02(3 \mathrm{H}, \mathrm{s}) ;{ }^{13} \mathrm{C} \mathrm{NMR}\left(125 \mathrm{MHz}, \mathrm{CDCl}_{3}\right) \delta 170.6,169.6$, 169.4, 169.3, 132.8, 117.7, 70.5, 69.2, 68.7, 67.1, 66.4, 60.3, 34.6, 20.7, 20.6, 20.5; HRMS (ESI): Calcd for $\mathrm{C}_{17} \mathrm{H}_{28} \mathrm{NO}_{9}\left[\mathrm{M}+\mathrm{NH}_{4}\right]^{+} 390.1764$, found 390.1777.

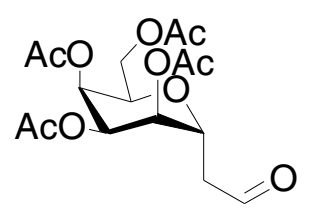

\section{2,3,4,6-tetra-O-acetyl- $\alpha$-D-talopyranosyl aldehyde (13)}

Ozone gas was bubbled through a solution of 12a $(0.86 \mathrm{~g}, 2.33 \mathrm{mmol})$ in $15 \mathrm{~mL}$ of dry $\mathrm{CH}_{2} \mathrm{Cl}_{2}$ at $-78{ }^{\circ} \mathrm{C}$ until the solution turned blue in color. Nitrogen was then bubbled through the solution until it turned colorless. Triphenylphosphine (1.5 g, $5.7 \mathrm{mmol})$ was then added, the solution was allowed to warm up to room temperature and stirred overnight. Dichloromethane was removed under reduced pressure and the residue was purified by flash column chromatography (toluene/acetone $4: 1$ ) to afford $\mathbf{1 3}$ in $85 \%$ yield.

${ }^{1} \mathrm{H}$ NMR $\left(500 \mathrm{MHz}, \mathrm{CDCl}_{3}\right) \delta 9.70(1 \mathrm{H}, \mathrm{t}, J=2.1 \mathrm{~Hz}), 5.56(1 \mathrm{H}, \mathrm{t}, J=3.0 \mathrm{~Hz}), 5.18(1 \mathrm{H}$, dd, $J=3.0,6.3 \mathrm{~Hz}), 4.90(1 \mathrm{H}, \mathrm{dd}, J=9.8,12.6 \mathrm{~Hz}), 4.77(1 \mathrm{H}, \mathrm{dd}, J=3.0,9.3 \mathrm{~Hz}), 4.53(1 \mathrm{H}$, ddd, $J=5.2,7.4,9.2 \mathrm{~Hz}), 4.23(1 \mathrm{H}$, ddd, $J=2.7,6.3,9.6 \mathrm{~Hz}), 4.07(1 \mathrm{H}, \mathrm{dd}, J=2.8,12.7$ $\mathrm{Hz}), 2.57-2.54(2 \mathrm{H}, \mathrm{m}), 2.15(3 \mathrm{H}, \mathrm{s}), 2.07(3 \mathrm{H}, \mathrm{s}), 2.05(3 \mathrm{H}, \mathrm{s}), 2.00(3 \mathrm{H}, \mathrm{s}) ;{ }^{13} \mathrm{C} \mathrm{NMR}$ $\left(125 \mathrm{MHz}, \mathrm{CDCl}_{3}\right) \delta 199.1,171.0,169.6,169.3,169.1,71.8,69.1,67.4,66.5,63.3,59.5$, 
44.9, 20.8, 20.8, 20.6, 20.5; HRMS (ESI): Calcd for $\mathrm{C}_{16} \mathrm{H}_{26} \mathrm{NO}_{10}\left[\mathrm{M}+\mathrm{NH}_{4}\right]^{+}$ 392.1556 , found 392.1568 .

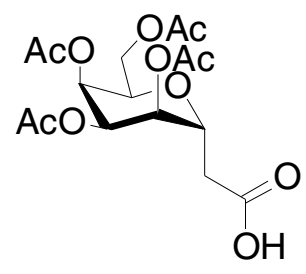

\section{2,3,4,6-tetra-O-acetyl- $\alpha$-D-talopyranosyl acid (14)}

To a solution of $13(2.0 \mathrm{~g}, 5.4 \mathrm{mmol})$ in $1: 1(\mathrm{v}: \mathrm{v})$ mixture of tert-butyl alcohol and 2methyl-2-butene $(20 \mathrm{~mL})$, an aqueous solution of potassium dihydrogen phosphate $(3.7$ g) and sodium chlorite $(2.4 \mathrm{~g})$ in $10 \mathrm{~mL}$ distilled water was added. The mixture was stirred vigorously at $0{ }^{\circ} \mathrm{C}$ for 6 hours. The product was extracted with EtOAc and washed with $100 \mathrm{~mL}$ water and $50 \mathrm{~mL}$ brine solution. The organic layer was then dried over $\mathrm{MgSO}_{4}$ and concentrated to afford 14 in $96 \%$ yield.

${ }^{1} \mathrm{H}$ NMR $\left(400 \mathrm{MHz}, \mathrm{CDCl}_{3}\right) \delta 5.57(1 \mathrm{H}, \mathrm{t}, J=3.0 \mathrm{~Hz}), 5.20(1 \mathrm{H}, \mathrm{dd}, J=3.1,6.2 \mathrm{~Hz}), 4.83$ $(1 \mathrm{H}, \mathrm{dd}, J=3.0,9.2 \mathrm{~Hz}), 4.76(1 \mathrm{H}, \mathrm{dd}, J=9.5,12.5 \mathrm{~Hz}), 4.38(1 \mathrm{H}$, ddd, $J=3.7,8.9,8.9 \mathrm{~Hz})$, 4.29 (1H, ddd, $J=3.0,6.2,9.3 \mathrm{~Hz}), 4.17(1 \mathrm{H}, \mathrm{dd}, 3.0,12.6 \mathrm{~Hz}), 2.62(1 \mathrm{H}, \mathrm{dd}, J=3.7,15.8$ $\mathrm{Hz}), 2.53(1 \mathrm{H}, \mathrm{dd}, J=8.8,15.8 \mathrm{~Hz}), 2.16(3 \mathrm{H}, \mathrm{s}), 2.08(3 \mathrm{H}, \mathrm{s}), 2.07(3 \mathrm{H}, \mathrm{s}), 2.03(3 \mathrm{H}, \mathrm{s})$; ${ }^{13} \mathrm{C}$ NMR $\left(100 \mathrm{MHz}, \mathrm{CDCl}_{3}\right) \delta 173.9,171.0,169.7,169.3,169.2,71.6,68.9,67.4,66.5$, 65.0, 59.8, 36.1, 20.9, 20.7, 20.6, 20.6; LRMS (ESI): Calcd for $\mathrm{C}_{16} \mathrm{H}_{23} \mathrm{O}_{11}[\mathrm{M}+\mathrm{H}]^{+}$391.3, found 391.4; HRMS (ESI): Calcd for $\mathrm{C}_{16} \mathrm{H}_{26} \mathrm{NO}_{11}\left[\mathrm{M}+\mathrm{NH}_{4}\right]^{+}$408.1505, found 408.1512 .

\section{(iii) Synthesis of C-linked glycoconjugate}

\section{$\underline{\text { Scheme } 3}$}

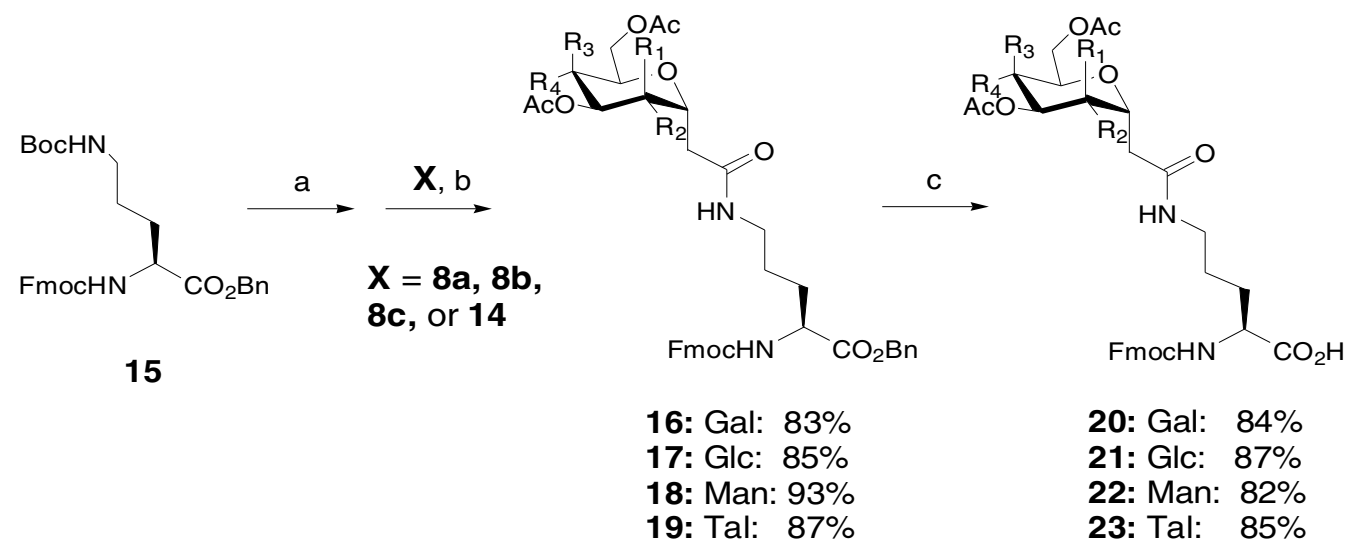

Conditions: (a) TFA/CH $\mathrm{CH}_{2}$; (b) HBTU, DIPEA, $\mathrm{CH}_{2} \mathrm{Cl}_{2}$; (c) $10 \% \mathrm{Pd} / \mathrm{C}, \mathrm{H}_{2}$, EtOH-EtOAc. 


\section{General Protocol for amide coupling of C-linked glycoconjugate}

To a solution of fully protected amino acid derivative $15(0.21 \mathrm{~g}, 0.38 \mathrm{mmol})$ in $10 \mathrm{~mL}$ of $\mathrm{CH}_{2} \mathrm{Cl}_{2}, 2 \mathrm{~mL}$ of TFA was added. The reaction was stirred for 40 minutes and then concentrated under reduced pressure. The syrup was re-dissolved in a 1:1 mixture of toluene and $\mathrm{CH}_{2} \mathrm{Cl}_{2}$, concentrated, then re-dissolved in diethyl ether and concentrated to afford a white solid. To a solution of carboxylic acid carbohydrate derivative $(0.15 \mathrm{~g}$, $0.38 \mathrm{mmol})$, HBTU $(0.17 \mathrm{~g}, 0.46 \mathrm{mmol})$ in $15 \mathrm{~mL}$ of $\mathrm{CH}_{2} \mathrm{Cl}_{2}$, and $0.20 \mathrm{~mL}(0.15 \mathrm{~g}, 1.14$ mmol) of DIPEA were added. The reaction was allowed to stir for 20 minutes and then the deprotected amino acid derivative was added. After stirring overnight, the reaction mixture was washed successively with saturated ammonium chloride, water, brine, dried over $\mathrm{MgSO}_{4}$ and concentrated. The product was purified by flash column chromatography in 50:1 $\mathrm{CH}_{2} \mathrm{Cl}_{2}$ and $\mathrm{MeOH}$ to afford a $\mathrm{C}$-linked glycosyl amide building block in $\sim 80 \%$ yield.

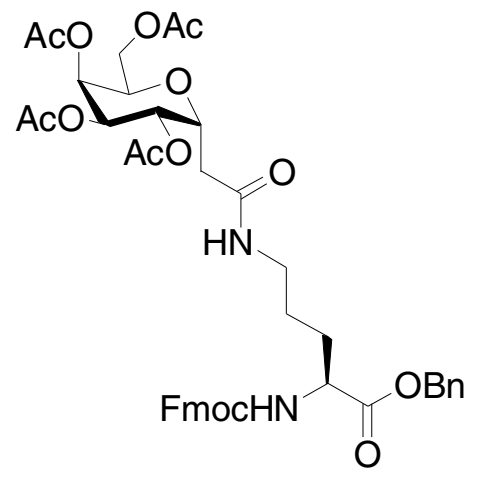

\section{Benzyl Fluorenylmethoxycarbonyl-L-ornithine-1-(2,3,4,6-tetra-O-acetyl- $\alpha$-D- galactopyranoside) (16)}

${ }^{1} \mathrm{H}$ NMR $\left(300 \mathrm{MHz}, \mathrm{CDCl}_{3}\right) \delta 7.76(2 \mathrm{H}, \mathrm{d}, J=7.5 \mathrm{~Hz}), 7.59(2 \mathrm{H}, \mathrm{d}, J=7.21 \mathrm{~Hz}), 7.42-7.28$ $(9 \mathrm{H}, \mathrm{m}), 6.12(1 \mathrm{H}$, br s), $5.55(1 \mathrm{H}, \mathrm{d}, J=8.4 \mathrm{~Hz}), 5.4(1 \mathrm{H}, \mathrm{t}, J=3.3 \mathrm{~Hz}), 5.29-5.23(1 \mathrm{H}, \mathrm{m})$, 5.17-5.12 (3H, m), 4.67-4.61 (1H, m), 4.46-4.34 (3H, m), 4.25-4.19 (2H, m), 4.15-4.09 $(2 \mathrm{H}, \mathrm{m}), 3.29-3.23(2 \mathrm{H}, \mathrm{m}), 2.57-2.47(1 \mathrm{H}, \mathrm{m}), 2.41-2.34(1 \mathrm{H}, \mathrm{m}), 2.10(3 \mathrm{H}, \mathrm{s}), 2.05(3 \mathrm{H}$, s), $2.04(3 \mathrm{H}, \mathrm{s}), 2.00(3 \mathrm{H}, \mathrm{s}), 1.93-1.82(1 \mathrm{H}, \mathrm{m}), 1.73-1.47(3 \mathrm{H}, \mathrm{m}) ;{ }^{13} \mathrm{C} \mathrm{NMR}(75 \mathrm{MHz}$, $\left.\mathrm{CDCl}_{3}\right) \delta 171.9,170.5,169.9,169.7,169.5,169.2,156.0,143.6,141.2,135.0,128.6$, $128.5,127.7,127.0,125.0,119.9,69.4,68.7,67.8,67.7,67.2,67.0,66.8,61.0,53.5,47.0$, 38.6, 34.4, 30.0, 25.3, 20.7, 20.6; LRMS (ESI): Calcd for $\mathrm{C}_{43} \mathrm{H}_{49} \mathrm{~N}_{2} \mathrm{O}_{14}[\mathrm{M}+\mathrm{H}]^{+} 817.8$, found 817.4 . 


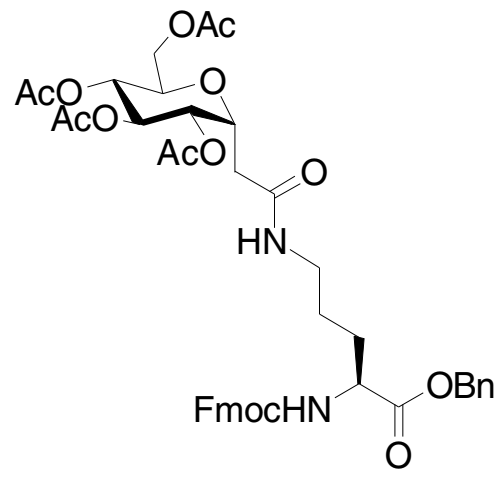

\section{Benzyl Fluorenylmethoxycarbonyl-L-ornithine-1-(2,3,4,6-tetra-O-acetyl- $\alpha$-D- glucopyranoside) (17)}

${ }^{1} \mathrm{H}$ NMR $\left(300 \mathrm{MHz}, \mathrm{CDCl}_{3}\right) \delta 7.76(2 \mathrm{H}, \mathrm{d}, J=7.4 \mathrm{~Hz}), 7.60(2 \mathrm{H}, \mathrm{d}, J=7.1 \mathrm{~Hz}), 7.45-7.25$ $(9 \mathrm{H}, \mathrm{m}), 6.17(1 \mathrm{H}$, br s), $5.64(1 \mathrm{H}, \mathrm{d}, J=7.9 \mathrm{~Hz}), 5.23(1 \mathrm{H}, \mathrm{t}, J=8.4 \mathrm{~Hz}), 5.20-5.04(3 \mathrm{H}$, $\mathrm{m}), 4.97(1 \mathrm{H}, \mathrm{t}, J=8.3 \mathrm{~Hz}), 4.25-4.12(3 \mathrm{H}, \mathrm{m}), 3.97-3.90(1 \mathrm{H}, \mathrm{m}), 3.35-3.17(2 \mathrm{H}, \mathrm{m}), 2.60$ $(1 \mathrm{H}, \mathrm{dd}, J=9.6,12.4 \mathrm{~Hz}), 2.45(1 \mathrm{H}, \mathrm{dd}, J=4.4,15.4 \mathrm{~Hz}), 2.07-1.98(12 \mathrm{H}, \mathrm{m}), 1.95-1.77$ $(1 \mathrm{H}, \mathrm{m}), 1.76-1.60(1 \mathrm{H}, \mathrm{m}), 1.60-1.46(2 \mathrm{H}, \mathrm{m}) ;{ }^{13} \mathrm{C} \mathrm{NMR}\left(75 \mathrm{MHz}, \mathrm{CDCl}_{3}\right) \delta 171.9$, $170.6,169.9,169.4,169.0,156.0,143.8,143.6,141.2,135.1,128.6,128.5,128.5,128.3$, 127.7, 127.0, 125.0, 119.9, 69.9, 69.7, 69.4, 69.3, 68.2, 67.3, 67.0, 62.0, 53.5, 47.1, 38.9, 38.6, 34.2, 30.0, 25.3, 20.7, 20.6, 20.6; HRMS (ESI): Calcd for $\mathrm{C}_{43} \mathrm{H}_{49} \mathrm{~N}_{2} \mathrm{O}_{14}[\mathrm{M}+\mathrm{H}]^{+}$ 817.3183, found 817.3192.

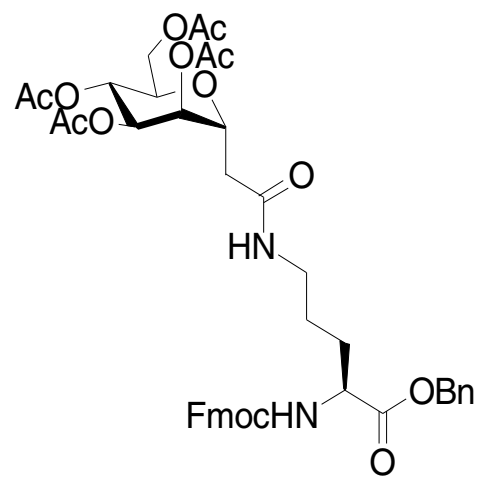

Benzyl Fluorenylmethoxycarbonyl-L-ornithine-1-(2,3,4,6-tetra-O-acetyl- $\alpha$-Dmannopyranoside) (18)

${ }^{1} \mathrm{H}$ NMR $\left(300 \mathrm{MHz}, \mathrm{CDCl}_{3}\right) \delta 7.76(2 \mathrm{H}, \mathrm{d}, J=7.4 \mathrm{~Hz}), 7.60(2 \mathrm{H}, \mathrm{d}, J=7.1 \mathrm{~Hz}), 7.44-7.25$ $(9 \mathrm{H}, \mathrm{m}), 6.18(1 \mathrm{H}$, br s), $5.71(1 \mathrm{H}, \mathrm{d}, J=8.1 \mathrm{~Hz}), 5.25(1 \mathrm{H}, \mathrm{dd}, J=3.2,7.2 \mathrm{~Hz}), 5.20-5.07$ $(3 \mathrm{H}, \mathrm{m}), 4.47-4.30(5 \mathrm{H}, \mathrm{m}), 4.25-4.15(2 \mathrm{H}, \mathrm{m}), 4.02-3.94(1 \mathrm{H}, \mathrm{m}), 3.40-3.20(2 \mathrm{H}, \mathrm{m})$, $2.52(2 \mathrm{H}, \mathrm{d}, J=6.87 \mathrm{~Hz}), 2.10-2.06(12 \mathrm{H}, \mathrm{m}), 2.00-1.82(1 \mathrm{H}, \mathrm{m}), 1.80-1.65(1 \mathrm{H}, \mathrm{m}), 1.64-$ $1.50(2 \mathrm{H}, \mathrm{m}) ;{ }^{13} \mathrm{C}$ NMR $\left(75 \mathrm{MHz}, \mathrm{CDCl}_{3}\right) \delta 172.0,170.6,169.9,169.8,169.5,168.8$, 156.1, 143.8, 143.6, 141.2, 135.1, 128.6, 128.6, 128.5, 128.5, 128.3, 127.7, 127.6, 127.0, 126.9. 125.0, 119.9, 72.0, 69.9, 69.1, 68.0, 67.3, 67.2, 67.0, 65.2, 61.7, 53.6, 47.1, 38.9, 38.6, 37.3, 29.9, 25.5, 20.7, 20.7, 20.6; HRMS (ESI): Calcd for $\mathrm{C}_{43} \mathrm{H}_{49} \mathrm{~N}_{2} \mathrm{O}_{14}[\mathrm{M}+\mathrm{H}]^{+}$ 817.3183, found 817.3198. 


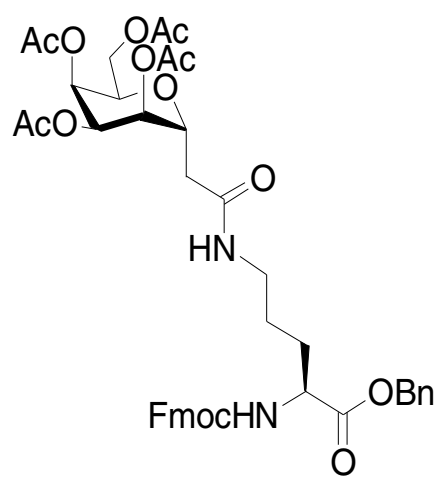

\section{Benzyl Fluorenylmethoxycarbonyl-L-ornithine-1-(2,3,4,6-tetra-O-acetyl- $\alpha$-D- talopyranoside) (19)}

${ }^{1} \mathrm{H}$ NMR $\left(500 \mathrm{MHz}, \mathrm{CDCl}_{3}\right) \delta 7.69(2 \mathrm{H}, \mathrm{d}, J=7.3 \mathrm{~Hz}), 7.52(2 \mathrm{H}, \mathrm{d}, J=7.8 \mathrm{~Hz}), 7.35-7.17$ $(9 \mathrm{H}, \mathrm{m}), 6.18-6.11(1 \mathrm{H}, \mathrm{m}), 5.54(1 \mathrm{H}, \mathrm{d}, J=7.6 \mathrm{~Hz}), 5.46(1 \mathrm{H}, \mathrm{t}, J=3.3 \mathrm{~Hz}), 5.14-5.05$ $(3 \mathrm{H}, \mathrm{m}), 4.70(1 \mathrm{H}, \mathrm{dd}, J=2.6,9.0 \mathrm{~Hz}), 4.55(1 \mathrm{H}, \mathrm{dd}, J=9.8,12.6 \mathrm{~Hz}), 4.40-4.00(7 \mathrm{H}, \mathrm{m})$, 3.23-3.10 $(2 \mathrm{H}, \mathrm{m}), 2.37(1 \mathrm{H}, \mathrm{dd}, J=2.7,15.1 \mathrm{~Hz}), 2.23(1 \mathrm{H}, \mathrm{dd}, J=9.0,14.8 \mathrm{~Hz}), 2.06$ $(3 \mathrm{H}, \mathrm{s}), 1.99(3 \mathrm{H}, \mathrm{s}), 1.96(3 \mathrm{H}, \mathrm{s}), 1.93(3 \mathrm{H}, \mathrm{s}), 1.87-1.77(1 \mathrm{H}, \mathrm{m}), 1.67-1.57(1 \mathrm{H}, \mathrm{m})$, 1.53-1.42 (2H, m); ${ }^{13} \mathrm{C}$ NMR $\left(125 \mathrm{MHz}, \mathrm{CDCl}_{3}\right) \delta 172.0,170.7,169.6,169.4,169.2$, 169.2, 156.0, 143.8, 143.6, 141.2, 135.1, 128.6, 128.5, 128.2, 127.6, 127.0, 125.0, 125.0, $119.9,71.7,69.0,67.4,67.2,67.0,66.4,65.6,60.1,53.6,47.0,38.9,38.5,38.2,29.9$, 25.4, 20.8, 20.8, 20.6; HRMS (ESI): Calcd for $\mathrm{C}_{43} \mathrm{H}_{49} \mathrm{~N}_{2} \mathrm{O}_{14}[\mathrm{M}+\mathrm{H}]^{+}$817.3183, found 817.3149 .

\section{General protocol for debenzylation of $\boldsymbol{C}$-linked glycoconjugate}

To a solution of benzyl ester in 1:1 ethanol/ethyl acetate, a catalytic amount $(8 \% \mathrm{w} / \mathrm{w})$ of palladium on charcoal $(10 \% \mathrm{w} / \mathrm{w})$ was added. The reaction mixture was stirred under $\mathrm{H}_{2}$ atmosphere and monitored via TLC. After the reaction was completed, the catalyst was gravity filtered through Whatman No.2 filter paper. The combined filtrates were concentrated and the compound was purified by column chromatography (5\% $\mathrm{MeOH} / \mathrm{CH}_{2} \mathrm{Cl}_{2}$ ) to afford a crystalline solid in $>80 \%$ yield. 


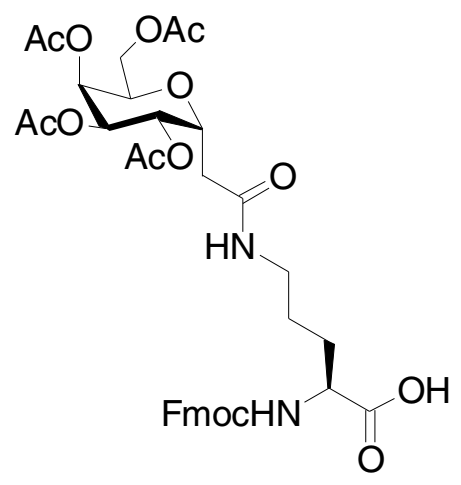

Fluorenylmethoxycarbonyl-L-ornithine-1-(2,3,4,6-tetra-O-acetyl- $\alpha-D-$ galactopyranoside) (20)

${ }^{1} \mathrm{H}$ NMR $\left(300 \mathrm{MHz}, \mathrm{CDCl}_{3}\right) \delta 7.76(2 \mathrm{H}, \mathrm{d}, J=7.2 \mathrm{~Hz}), 7.60(2 \mathrm{H}, \mathrm{d}, J=6 \mathrm{~Hz}), 7.42-7.37$ $(2 \mathrm{H}, \mathrm{m}), 7.33-7.28(2 \mathrm{H}, \mathrm{m}) 6.25(1 \mathrm{H}, \mathrm{br} \mathrm{s}), 5.6(1 \mathrm{H}, \mathrm{d}, J=7.5 \mathrm{~Hz}), 5.39(1 \mathrm{H}, \mathrm{t}, J=3.3 \mathrm{~Hz})$, 5.27-5.23 (1H, m), 5.16-5.12 (1H, m), 4.68-4.63 (1H, m), 4.39 (2H, d, J=6.6), 4.33-4.05 $(5 \mathrm{H}, \mathrm{m}), 3.37-3.25(2 \mathrm{H}, \mathrm{m}), 2.60(1 \mathrm{H}, \mathrm{dd}, J=15.5,9.8 \mathrm{~Hz}), 2.44(1 \mathrm{H}, \mathrm{dd}, J=15.5,4.2 \mathrm{~Hz})$, $2.11(3 \mathrm{H}, \mathrm{s}), 2.05(3 \mathrm{H}, \mathrm{s}), 2.04(3 \mathrm{H}, \mathrm{s}), 2.02(3 \mathrm{H}, \mathrm{s}), 1.98-1.86(1 \mathrm{H}, \mathrm{m}), 1.82-1.69(1 \mathrm{H}$, $\mathrm{m}), 1.70-1.54(2 \mathrm{H}, \mathrm{m}) ;{ }^{13} \mathrm{C} \mathrm{NMR}\left(100 \mathrm{MHz}, \mathrm{CDCl}_{3}\right) \delta 174.4,172.4,170.9,170.4,170.0$, 169.8, 156.1, 143.6, 141.2, 127.7, 127.0, 125.0, 119.9, 69.1, 68.9, 67.8, 67.7, 66.9, 61.2, 53.4, 50.6, 47.0, 39.1, 34.1, 31.7, 28.6, 22.1, 20.7; IR (thin film): $3367,1748 \mathrm{~cm}^{-1}$; LRMS (ESI): Calcd for $\mathrm{C}_{36} \mathrm{H}_{43} \mathrm{~N}_{2} \mathrm{O}_{14}[\mathrm{M}+\mathrm{H}]^{+} 726.3$, found 727.0 .

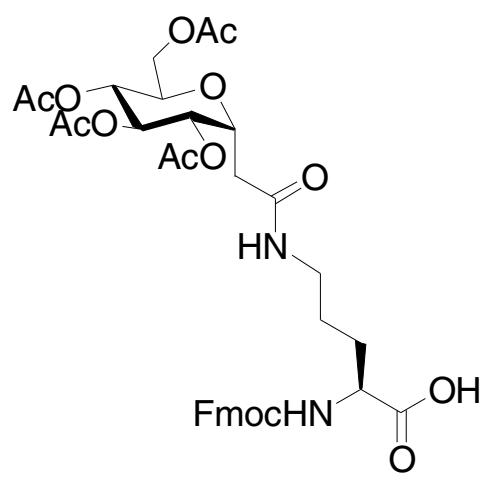

Fluorenylmethoxycarbonyl-L-ornithine-1-(2,3,4,6-tetra-O-acetyl- $\alpha-D-$ glucopyranoside) (21)

${ }^{1} \mathrm{H}$ NMR (300 MHz, $\left.\mathrm{CDCl}_{3}\right) \delta 7.75(2 \mathrm{H}, \mathrm{d}, J=7.6 \mathrm{~Hz}), 7.63-7.55(2 \mathrm{H}, \mathrm{m}), 7.38(2 \mathrm{H}, \mathrm{t}$, $J=7.4 \mathrm{~Hz}), 7.33-7.25(2 \mathrm{H}, \mathrm{m}), 6.64-6.53(1 \mathrm{H}, \mathrm{m}), 5.83(1 \mathrm{H}, \mathrm{d}, J=7.4 \mathrm{~Hz}), 5.24(1 \mathrm{H}, \mathrm{t}$, $J=8.3 \mathrm{~Hz}), 5.07(1 \mathrm{H}, \mathrm{dd}, J=5.2,8.6 \mathrm{~Hz}), 4.98(1 \mathrm{H}, \mathrm{t}, J=8.3 \mathrm{~Hz}), 4.70-4.60(1 \mathrm{H}, \mathrm{m}), 4.45-$ $4.30(3 \mathrm{H}, \mathrm{m}), 4.25-4.12(2 \mathrm{H}, \mathrm{m}), 4.05-3.90(3 \mathrm{H}, \mathrm{m}), 3.40-3.20(2 \mathrm{H}, \mathrm{m}), 2.66(2 \mathrm{H}, \mathrm{dd}$, $J=9.9,15.2 \mathrm{~Hz}), 2.49(2 \mathrm{H}, \mathrm{dd}, J=4.3,15.3 \mathrm{~Hz}), 2.05(3 \mathrm{H}, \mathrm{s}), 2.03(3 \mathrm{H}, \mathrm{s}), 2.02(3 \mathrm{H}, \mathrm{s})$, $2.01(3 \mathrm{H}, \mathrm{s}), 1.97-1.82(1 \mathrm{H}, \mathrm{m}), 1.81-1.67(1 \mathrm{H}, \mathrm{m}), 1.67-1.51(2 \mathrm{H}, \mathrm{m}) ;{ }^{13} \mathrm{C} \mathrm{NMR}(75$ $\left.\mathrm{MHz}, \mathrm{CDCl}_{3}\right) \delta 171.0,170.0,169.6,169.5,156.3,143.8,143.7,141.3,127.7,127.1$, 125.1, 120.0, 77.2, 69.9, 69.7, 69.5, 69.4, 68.2, 67.1, 62.1, 53.5, 47.1, 39.1, 34.2, 29.8, 25.2, 20.7, 20.7, 20.6, 20.6; HRMS (ESI): Calcd for $\mathrm{C}_{36} \mathrm{H}_{43} \mathrm{~N}_{2} \mathrm{O}_{14}[\mathrm{M}+\mathrm{H}]^{+}$727.2714, found 727.2739 . 


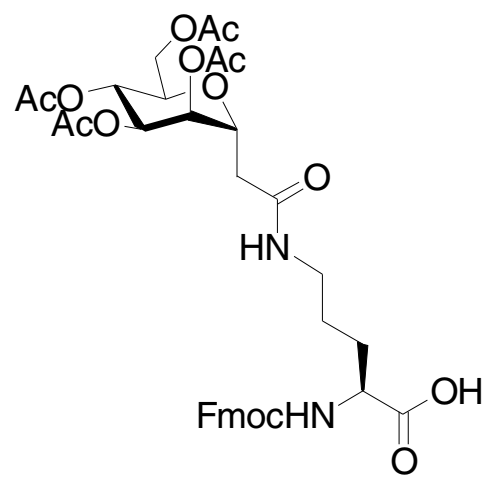

Fluorenylmethoxycarbonyl-L-ornithine-1-(2,3,4,6-tetra-O-acetyl- $\alpha$-Dmannopyranoside) (22)

${ }^{1} \mathrm{H}$ NMR $\left(300 \mathrm{MHz}, \mathrm{CDCl}_{3}\right) \delta 7.74(2 \mathrm{H}, \mathrm{d}, J=7.4 \mathrm{~Hz}), 7.58(2 \mathrm{H}, \mathrm{dd}, J=4.8,7.1 \mathrm{~Hz}), 7.37$ $(2 \mathrm{H}, \mathrm{dd}, 7.2,7.9 \mathrm{~Hz}), 7.27(2 \mathrm{H}, \mathrm{dt}, J=1.1,7.7,7.8 \mathrm{~Hz}), 6.72(1 \mathrm{H}$, br m), $5.94(1 \mathrm{H}, \mathrm{d}$, $J=7.5 \mathrm{~Hz}), 5.24(1 \mathrm{H}, \mathrm{dd}, J=3.1,7.4 \mathrm{~Hz}), 5.15-5.08(2 \mathrm{H}, \mathrm{m}), 4.45-4.30(4 \mathrm{H}, \mathrm{m}), 4.22-4.12$ $(2 \mathrm{H}, \mathrm{m}), 4.02-3.92(1 \mathrm{H}, \mathrm{m}), 3.38-3.20(2 \mathrm{H}, \mathrm{m}), 2.65-2.45(2 \mathrm{H}, \mathrm{m}), 2.05(3 \mathrm{H}, \mathrm{s}), 2.04(3 \mathrm{H}$, s), $2.03(6 \mathrm{H}, \mathrm{s}), 1.97-1.82(1 \mathrm{H}, \mathrm{m}), 1.80-1.65(1 \mathrm{H}, \mathrm{m}), 1.65-1.52(2 \mathrm{H}, \mathrm{m}) ;{ }^{13} \mathrm{C}$ NMR $(75$ $\left.\mathrm{MHz}, \mathrm{CDCl}_{3}\right) \delta 174.5,170.9,170.2,169.9,169.8,169.5,156.3,143.7,143.6,141.2$, 127.7, 127.0, 125.0, 119.9, 77.2, 71.7, 70.1, 69.3, 68.0, 67.2, 67.0, 61.8, 53.4, 47.0, 39.1, 36.9, 29.6, 25.2, 20.7, 20.7, 20.7, 20.6; HRMS (ESI): Calcd for $\mathrm{C}_{36} \mathrm{H}_{43} \mathrm{~N}_{2} \mathrm{O}_{14}[\mathrm{M}+\mathrm{H}]^{+}$ 727.2714, found 727.2715.

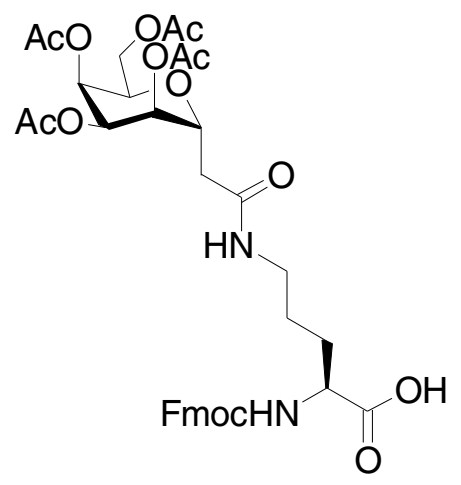

Fluorenylmethoxycarbonyl-L-ornithine-1-(2,3,4,6-tetra-O-acetyl- $\alpha-D-$ talopyranoside) (23)

${ }^{1} \mathrm{H}$ NMR $\left(400 \mathrm{MHz}, \mathrm{CDCl}_{3}\right) \delta$ 9.3-8.2 (1H, br s), $7.74(2 \mathrm{H}, \mathrm{d}, J=7.4 \mathrm{~Hz}), 7.59(2 \mathrm{H}, \mathrm{d}$, $J=6.9 \mathrm{~Hz}), 7.33(4 \mathrm{H}, \mathrm{dt}, J=7.1,28.6 \mathrm{~Hz}), 6.73(1 \mathrm{H}$, br s), $5.99(1 \mathrm{H}$, br d, $J=5.6 \mathrm{~Hz}), 5.52$ $(1 \mathrm{H}$, br s), $5.16(1 \mathrm{H}$, br dd, $J=3.0,5.2), 4.80(1 \mathrm{H}$, br dd, $J=2.2,8.3 \mathrm{~Hz}), 4.62(1 \mathrm{H}$, br dd, $J=9.8,12.6 \mathrm{~Hz}), 4.50-4.11(6 \mathrm{H}, \mathrm{m}), 3.4-3.15(2 \mathrm{H}$, br m), 2.58-2.30 (2H, br m), $2.12(3 \mathrm{H}$, s), $2.06(3 \mathrm{H}, \mathrm{s}), 2.03(3 \mathrm{H}, \mathrm{s}), 2.00(3 \mathrm{H}, \mathrm{s}), 1.96-1.83(1 \mathrm{H}, \mathrm{m}), 1.80-1.66(1 \mathrm{H}, \mathrm{m}), 1.66-$ $1.52(2 \mathrm{H}, \mathrm{m}) ;{ }^{13} \mathrm{C}$ NMR $\left(100 \mathrm{MHz}, \mathrm{CDCl}_{3}\right) \delta 171.0,170.2,169.7,169.5,156.3,143.8$, 143.6, 141.2, 127.7, 127.0, 125.1, 120.0, 71.5, 68.9, 67.3, 66.9, 66.4, 66.0, 60.3, 47.0, 39.0, 37.9, 29.7, 25.3, 20.8, 20.8, 20.6; HRMS (ESI): Calcd for $\mathrm{C}_{36} \mathrm{H}_{43} \mathrm{~N}_{2} \mathrm{O}_{14}[\mathrm{M}+\mathrm{H}]^{+}$ 727.2714 , found 727.2701 . 
(iv) Solid Phase Synthesis of C-Linked Glycopeptides

General protocol for manual and automated solid phase synthesis of C-linked analogues

All polypeptides were prepared by linear solid-phase synthesis using standard Fmoc chemistry. $^{2} \quad$ A typical procedure started from Fmoc-glycine Wang resin with loading capacities of $\sim 0.066 \mathrm{mmol} / \mathrm{g}$. The resin was swollen in DMF for 30 minutes. The solvent was then drained and $20 \%$ piperidine solution in DMF was added. The solution was allowed to stir for 1 hour, then it was drained, and the resin was washed with three aliquots of DMF. Kaiser and TNBS tests for free amine were then performed. Building block (1.5 equivalents) was premixed with 1.5 equivalents of HBTU in DMF, followed by the addition of 1.5 equivalents of DIPEA in DMF. The reaction was stirred for 30 minutes, transferred to the SPS flask and stirred for 24 hours. The flask was drained and the resin was rinsed three times with DMF. Kaiser and TNBS tests were performed to verify the coupling had reached completion (negative test outcome). The resin was treated with $20 \%$ piperdine in DMF solution for 1 hour, the flask was drained and the resin was washed thoroughly with DMF. Kaiser and TNBS tests were performed to ensure the presence of free amine. Then the next successive building block (5 equivalents) to be coupled (commercially available amino acid) was premixed with 5 equivalents of HBTU and 5 equivalents of DIPEA in DMF for 20 minutes. The reaction solution was then transferred to the resin, and the reaction mixture was allowed to stir for 4 hours. The Fmoc deprotection and coupling steps were repeated until twelve amino acid residues were coupled to the resin. To cleave the glycopeptide from the resin, the resin was successively rinsed with $\mathrm{DMF}, \mathrm{MeOH}$, and $\mathrm{CH}_{2} \mathrm{Cl}_{2}$, and stirred for 2 hours in 1:1 (v:v) trifluoroacetic acid and $\mathrm{CH}_{2} \mathrm{Cl}_{2}$. The solution was filtered and concentrated, and the product crystallized from diethyl ether to produce a white powder. The glycopolymer was dissolved in a sodium methoxide $(\mathrm{pH}=10)$ solution $(4: 1$ sodium methoxide/ water) and stirred for 5 hours. The solution was neutralized with IR-120 ion exchange resin, filtered, concentrated to remove $\mathrm{MeOH}$ and lyophilized to give the product as a white powder. Purification via HPLC using reverse phase chromatography (C-18 column, liquid phase: $0.1 \%$ TFA in acetonitrile/water) was then performed to obtain the desired glyopeptide.

\section{[L-Ornithine(galactose)-glycine-glycine $]_{4}$-glycine (1)}

${ }^{1} \mathrm{H}$ NMR $\left(300 \mathrm{MHz}, \mathrm{D}_{2} \mathrm{O}\right) \delta$ 4.42-4.32 (4H, m), 4.28-4.18 (4H, m), 4.00-3.80 (29H, m), 3.75-3.67 (4H, m), 3.67-3.47 (14H, m), 3.20-3.05 (8H, m), 2.62-2.42 (8H, m), 1.85-1.70 $(5 \mathrm{H}, \mathrm{m}), 1.70-1.57(4 \mathrm{H}, \mathrm{m}), 1.57-1.37(9 \mathrm{H}, \mathrm{m}) ;{ }^{13} \mathrm{C} \mathrm{NMR}\left(75 \mathrm{MHz}, \mathrm{D}_{2} \mathrm{O}\right) \delta 175.0,174.9$, $174.1,173.9,173.6,172.3,172.3,172.2$, 172.0, 171.9, 171.8, 170.7, 163.6, 163.1, 73.3, 72.8, 70.0, 69.1, 67.9, 61.2, 54.1, 53.2, 42.9, 42.7, 41.5, 41.4, 39.1, 32.7, 28.4, 25.2; LRMS (MALDI-TOF): Calcd for $\mathrm{C}_{70} \mathrm{H}_{117} \mathrm{~N}_{17} \mathrm{O}_{38}[\mathrm{M}+\mathrm{H}]^{+}$1805.8, found 1805.3.

\footnotetext{
${ }^{2}$ Fields, G. B.; Fields, C. G. J. Am. Chem. Soc. 1991, 113, 4202.
} 


\section{[L-Ornithine(glucose)-glycine-glycine $]_{4}$-glycine (2)}

${ }^{1} \mathrm{H}$ NMR (360 MHz, D $\left.{ }_{2} \mathrm{O}\right) \delta 4.47(32 \mathrm{H}, \mathrm{s}), 4.08$ (2H, br s), $3.73(6 \mathrm{H}, \mathrm{m}), 3.32(10 \mathrm{H}, \mathrm{m})$, $3.01(6 \mathrm{H}, \mathrm{m}), 2.45(2 \mathrm{H}, \mathrm{m}), 2.19(18 \mathrm{H}, \mathrm{s}), 1.98(8 \mathrm{H}, \mathrm{s}), 1.68(8 \mathrm{H}, \mathrm{m}), 1.30(4 \mathrm{H}, \mathrm{m}), 0.87$ $(2 \mathrm{H}, \mathrm{m}) ;{ }^{13} \mathrm{C}$ NMR $\left(90 \mathrm{MHz}, \mathrm{D}_{2} \mathrm{O}\right) \delta 187.76,186.77,185.19,184.83,184.24,180.00$, $159.30,143.77,142.41,142.34,139.011,138.55,97.19,86.21,85.68,82.81,81.66$, 80.76, 80.63, 74.08, 71.31, 66.13, 60.96, 55.79, 55.60, 51.98, 45.61, 45.43, 38.05, 36.468, 19.55; LRMS (ESI): Calcd for $\mathrm{C}_{70} \mathrm{H}_{117} \mathrm{~N}_{17} \mathrm{O}_{38}[\mathrm{M}+\mathrm{H}]^{+}$1805.8, found 1805.2

\section{[L-Ornithine(mannose)-glycine-glycine $]_{4}$-glycine (3)}

${ }^{1} \mathrm{H}$ NMR (500 MHz, D $\left.2 \mathrm{O}\right) \delta 4.83(32 \mathrm{H}, \mathrm{m}), 4.45(4 \mathrm{H}, \mathrm{m}), 4.07(6 \mathrm{H}, \mathrm{m}), 3.93(8 \mathrm{H}, \mathrm{m})$, $3.65(4 \mathrm{H}, \mathrm{m}), 3.46(4 \mathrm{H}, \mathrm{m}), 3.21(3 \mathrm{H}, \mathrm{m}), 2.98(1 \mathrm{H}, \mathrm{m}), 2.80(4 \mathrm{H}, \mathrm{m}), 2.68(1 \mathrm{H}, \mathrm{m}), 2.58$ $(1 \mathrm{H}, \mathrm{m}), 2.25(4 \mathrm{H}, \mathrm{m}), 2.07(16 \mathrm{H}, \mathrm{m}), 1.79(4 \mathrm{H}, \mathrm{m}), 1.60(8 \mathrm{H}, \mathrm{m}), 1.33(8 \mathrm{H}, \mathrm{m}), 1.06$ $(4 \mathrm{H}, \mathrm{m}) ;{ }^{13} \mathrm{C}$ NMR $\left(125 \mathrm{MHz}, \mathrm{D}_{2} \mathrm{O}\right) \delta 181.01,170.59,117.47,117.05,74.60,74.33$, 74.07, 70.34, 70.06, 66.70, 62.04, 60.51, 42.73, 42.07, 41.95, 38.29, 35.01, 34.79, 29.77, 27.69, 24.29, 22.81; LRMS (ESI): Calcd for $\mathrm{C}_{70} \mathrm{H}_{117} \mathrm{~N}_{17} \mathrm{O}_{38}[\mathrm{M}+\mathrm{H}]^{+}$1805.8, found 1804.1.

\section{[L-Ornithine(2,3,4,6-peracetylated talose)-glycine-glycine $]_{4}$-glycine}

${ }^{1} \mathrm{H}$ NMR (300 MHz, MeOD) $\delta 5.51(1 \mathrm{H}$, br s), $5.21(1 \mathrm{H}$, br s), 4.65-4.53 $(1 \mathrm{H}, \mathrm{m}), 4.46-$ $3.82(10 \mathrm{H}, \mathrm{m}), 3.24(3 \mathrm{H}, \mathrm{m}), 2.60-2.45(2 \mathrm{H}, \mathrm{m}), 2.11(3 \mathrm{H}, \mathrm{s}), 2.08(3 \mathrm{H}, \mathrm{s}), 2.06(6 \mathrm{H}, \mathrm{s})$, 1.97-1.83 (1H, m), 1.83-1.72 (1H, m), 1.72-1.52 (2H, m); ${ }^{13} \mathrm{C}$ NMR (75 MHz, MeOD) $\delta$ $174.3,174.0,171.9,171.5,171.4,171.1,170.8,170.5,170.5,170.4,71.1,69.4,68.1$, 67.5, 67.0, 60.9, 53.9, 53.9, 53.2, 42.7, 40.9, 39.2, 38.9, 37.6, 29.8, 28.7, 25.9, 25.0, 24.9, 22.8, 20.0, 19.8, 19.7, 19.7; LRMS (MALDI-TOF): Calcd for $\mathrm{C}_{102} \mathrm{H}_{149} \mathrm{~N}_{17} \mathrm{O}_{54}[\mathrm{M}+\mathrm{H}]^{+}$ 2478.4 , found 2476.8 .

\section{[L-Ornithine(talose)-glycine-glycine $]_{4}$-glycine (4)}

${ }^{1} \mathrm{H}$ NMR (500 MHz, D $\left.2 \mathrm{O}\right) \delta$ 4.27-4.17 (5H, m), 3.92-3.72 $(20 \mathrm{H}, \mathrm{m}), 3.67-3.55(7 \mathrm{H}, \mathrm{m})$, 3.45-3.40 (1H, m), 3.14-3.07 (6H, m), 2.54-2.40 (6H, m), 1.80-1.70 (2H, m), 1.70-1.55 $(3 \mathrm{H}, \mathrm{m}), 1.55-1.37(6 \mathrm{H}, \mathrm{m}) ;{ }^{13} \mathrm{C} \mathrm{NMR}\left(125 \mathrm{MHz}, \mathrm{D}_{2} \mathrm{O}\right) \delta 174.4,172.6,171.8,171.5$, $170.9,99.9,73.9,72.9,72.8,70.6,68.8,66.8,60.0,53.8,53.5,43.0,42.4,42.3,42.2$, 38.8, 38.6, 36.0, 28.0, 24.7, 24.6, 24.4; LRMS (MALDI-TOF): Calcd for $\mathrm{C}_{70} \mathrm{H}_{117} \mathrm{~N}_{17} \mathrm{O}_{38}$ $[\mathrm{M}+\mathrm{H}]^{+} 1805.8$, found 1804.8 . 


\section{Assessing Antifreeze Activity:}

Antifreeze activity of analogues 1-4 was evaluated using two standard methods. Thermal hysteresis (TH) was measured using a Clifton Nanoliter Osmometer ${ }^{3}$ and recrystallization-inhibition (RI) activity was assessed using the splat cooling technique previously described by Knight and co-workers. ${ }^{4}$ Briefly, the latter technique involves generating a frozen wafer from the analyte which is dissolved in phosphate buffered saline (PBS) solution; a $10 \mathrm{uL}$ drop of this solution is then dropped from a pipette through a two metre high plastic tube $(10 \mathrm{~cm}$ in diameter) onto a block of polished aluminum pre-cooled to approximately $-80{ }^{\circ} \mathrm{C}$. The droplet freezes instantly on the polished aluminum block and is approximately $1 \mathrm{~cm}$ in diameter and $20 \mathrm{um}$ thick. This wafer is then carefully removed from the surface of the block and transferred to a cryostage (refrigerated microscope stage) held at $-6.4{ }^{\circ} \mathrm{C}$. The wafer is left to anneal at this temperature for a period of $30 \mathrm{mins}$ and then photographed between crossed polarizing filters using a digital camera (Nikon CoolPix 5000) fitted to the microscrope. A total of six different images are taken from each wafer; three from the middle and three from the edge. The images are then analyzed using the mean elliptical method. In this method, the ten largest ice crystals were chosen from the field of view (FOV) in each image. ${ }^{5,6}$ Selection of these crystals was arbitrary in that they were chosen after a visual inspection of the image. The two dimensional surface area of each of these ten crystals was then calculated via approximation of the crystal as an elliptical area. The major and minor elliptical axes were defined by the two largest orthogonal dimensions across the ice grain surface. The surface area of each ice grain was then calculated based on the formula: $\mathrm{A}=\pi \mathrm{ab}$, in which $\mathrm{A}$ represented area; $\mathrm{a}$ and $\mathrm{b}$ represented the length of the major and minor elliptical axes. Totalling all individual measurements for each FOV produces a value for the average grain surface area referred to as the mean largest grain size (MLGS). Error was calculated using standard error of the mean (SEM). T-tests were performed to a $95 \%$ confidence level.

\section{Conformational Analysis via Circular Dichroism}

Circular Dichroism was performed on JASCO Model J-810 automatic spectrophotometer interfaced with Acer computer. Spectral data were obtained with the following parameters: $1 \mathrm{~nm}$ bandwidth; four scans at a scan speed of $50 \mathrm{~nm} / \mathrm{min} ; 190-350 \mathrm{~nm}$ wavelength range. Samples were measured at $22{ }^{\circ} \mathrm{C}$ in a quartz cell (Hellma QS) with a $1 \mathrm{~cm}$ path length. A molar concentration of $43 \mu \mathrm{M}$ was used for each sample, diluted in doubly distilled water. Data obtained from CD spectroscopy was converted into molar ellipticity ( $\mathrm{deg} \mathrm{cm}^{2} \mathrm{dmol}^{-1}$ ). Glycopeptide secondary structures were estimated using the deconvolution software CD Pro (SELCON 3 program and IBASIS 4 protein dataset). ${ }^{7}$

\footnotetext{
${ }^{3}$ Chakrabartty, A.; Hew, C.L.; Eur. J. Biochem. 1991, 202, 1057.

${ }^{4}$ Knight, C. A.; Hallett, J.; DeVries, A.L. Cryobiology 1988, 25, 55.

${ }^{5}$ Eniade, A.; Purushotham, M.; Ben, R.N.; Wang, J.B.; Horwath, K. Cell Biochem. Biophys. 2003, $38,115$.

${ }^{6}$ Liu, S.; Ben, R.N. Org. Lett. 2005, 7, 2385.

${ }^{7}$ (a) Sreerama, N.; Venyaminov, S.Y.; Woody, R.W. Anal. Biochem. 2000, 287, 243. (b) Sreerama, N.; Woody, R.W. Anal. Biochem. 2000, 287, 252-260. (c) Greenfield, N. J. Anal. Biochem. 1996, 35, 1-10.
} 


\begin{tabular}{|c|c|c|c|c|c|c|c|c|}
\hline IBASIS 4 & \multicolumn{6}{|c|}{ Conformation } & \multicolumn{2}{|c|}{} \\
\hline & $\begin{array}{c}\text { Regular } \\
\alpha \text {-Helix }\end{array}$ & Distorted & Regular & Distorted \\
$\beta$-Strand & $\beta$-Strand & Turn & $\begin{array}{c}\text { Random } \\
\text { coil }\end{array}$ & Sum & NRMSD \\
\hline OGG Gal (1) & -0.011 & 0.160 & 0.031 & 0.092 & 0.256 & 0.504 & 1.032 & 0.543 \\
\hline OGG Glc (2) & -0.012 & 0.172 & -0.004 & 0.073 & 0.232 & 0.568 & 1.029 & 0.425 \\
\hline OGG Man (3) & 0.010 & 0.164 & 0.008 & 0.007 & 0.225 & 0.540 & 0.954 & 0.440 \\
\hline OGG Tal (4) & 0.020 & 0.049 & 0.084 & 0.101 & 0.248 & 0.529 & 1.031 & 0.407 \\
\hline AFGP-8 & 0.049 & 0.114 & 0.164 & 0.094 & 0.237 & 0.378 & 1.036 & 0.833 \\
\hline
\end{tabular}

Table 1. Deconvolution data for AFGP-8, $C$-linked analogues 1-4, using SELCON 3 and IBASIS 4. 


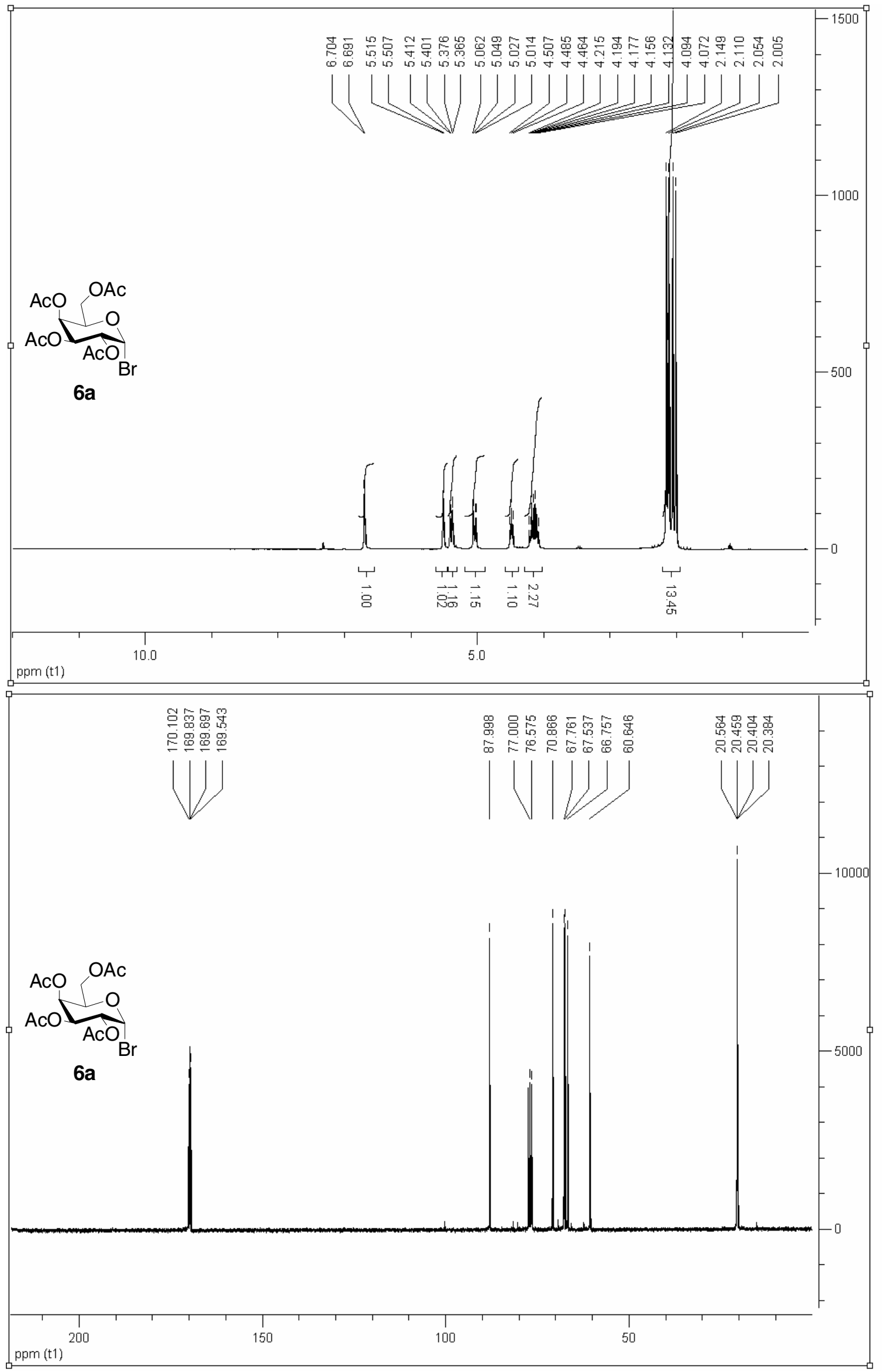




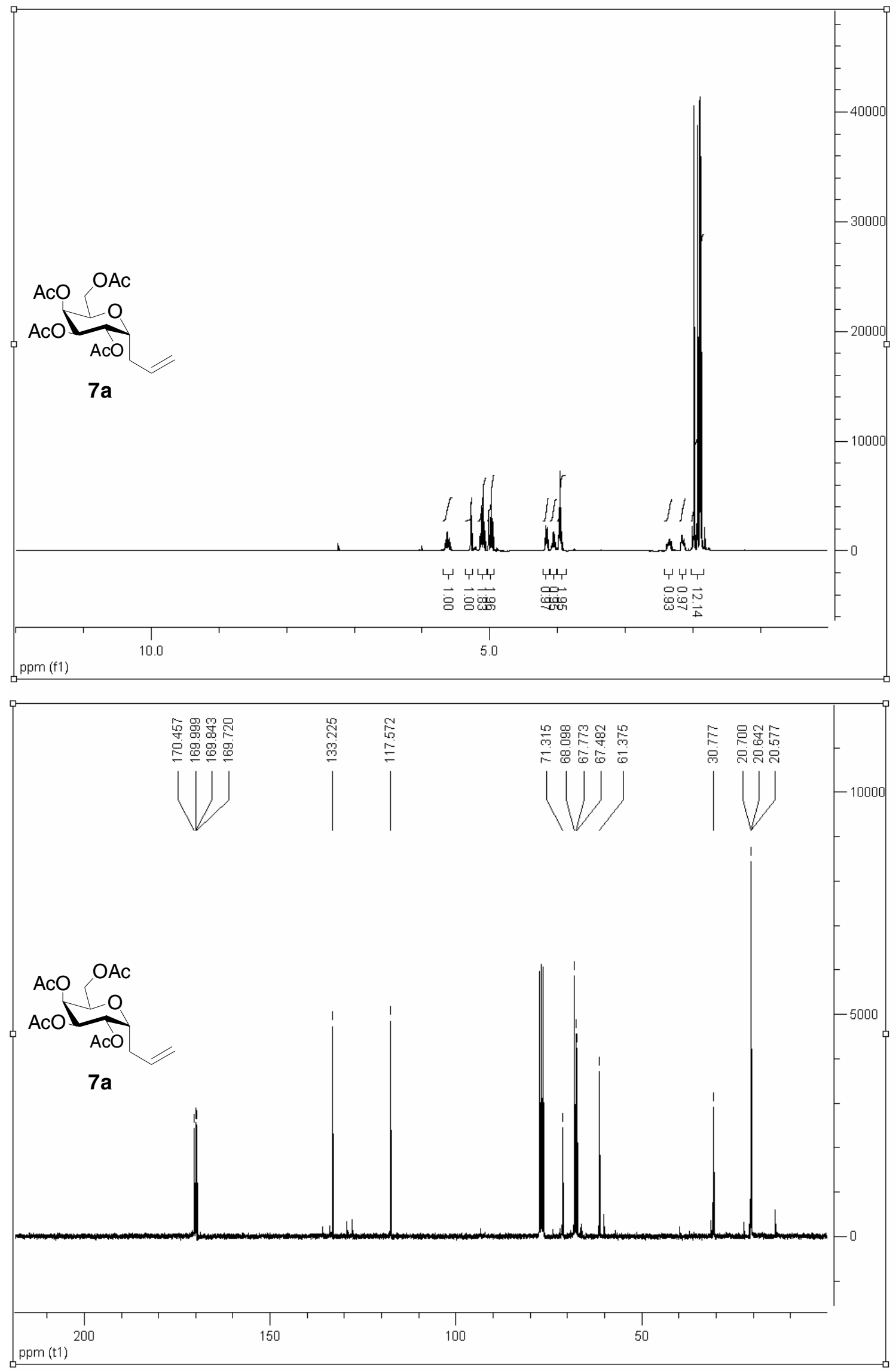



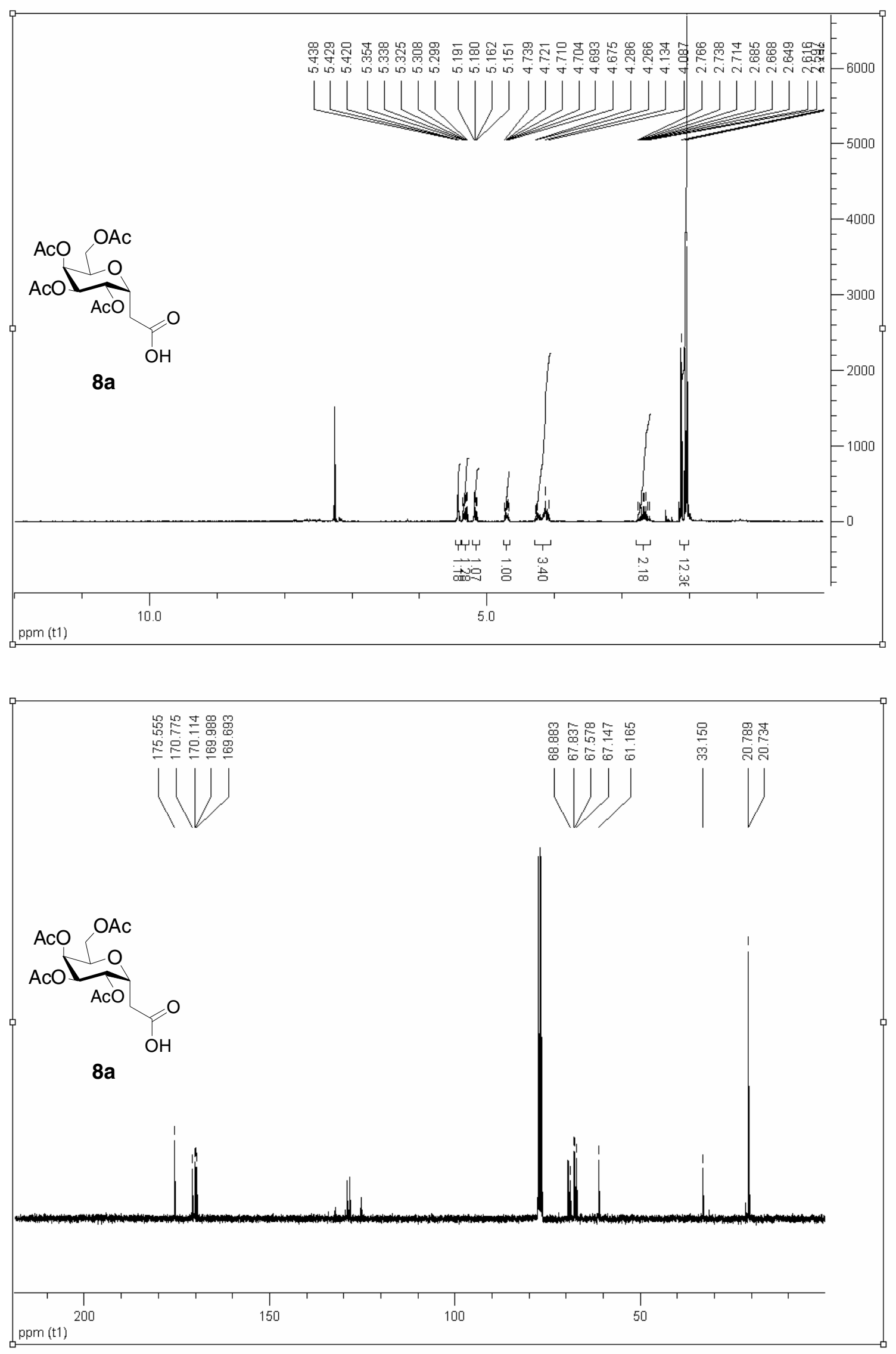

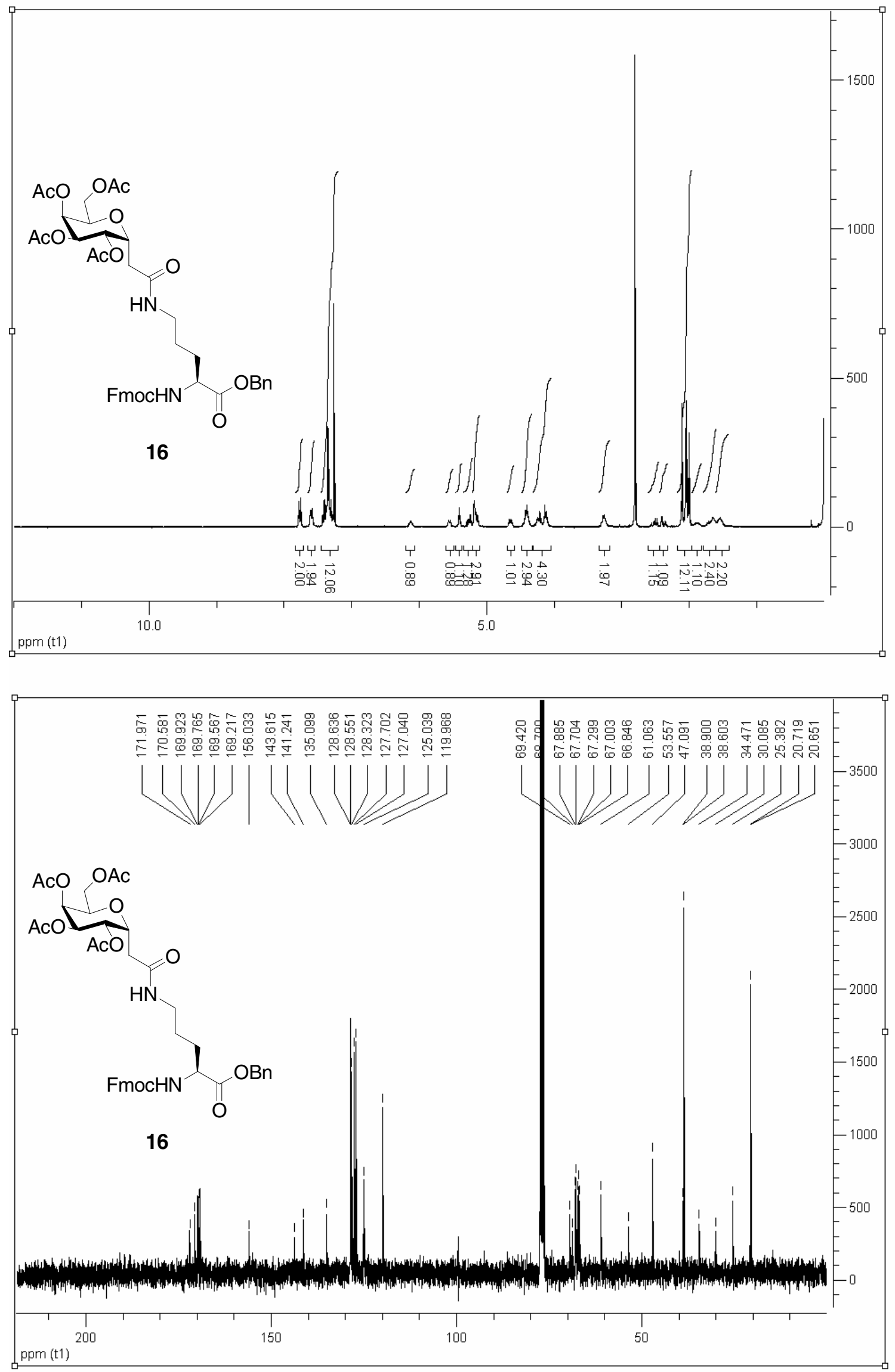

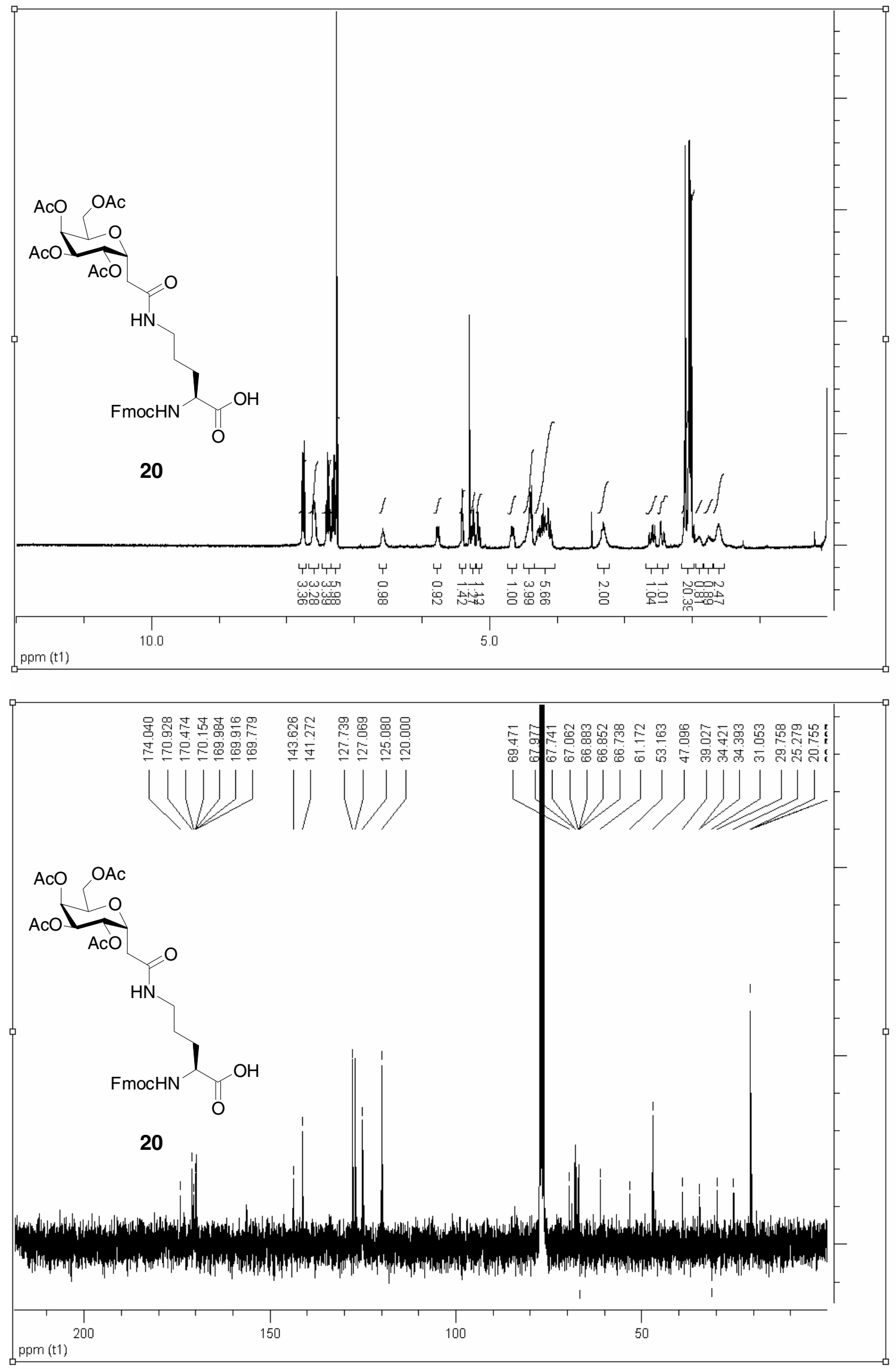

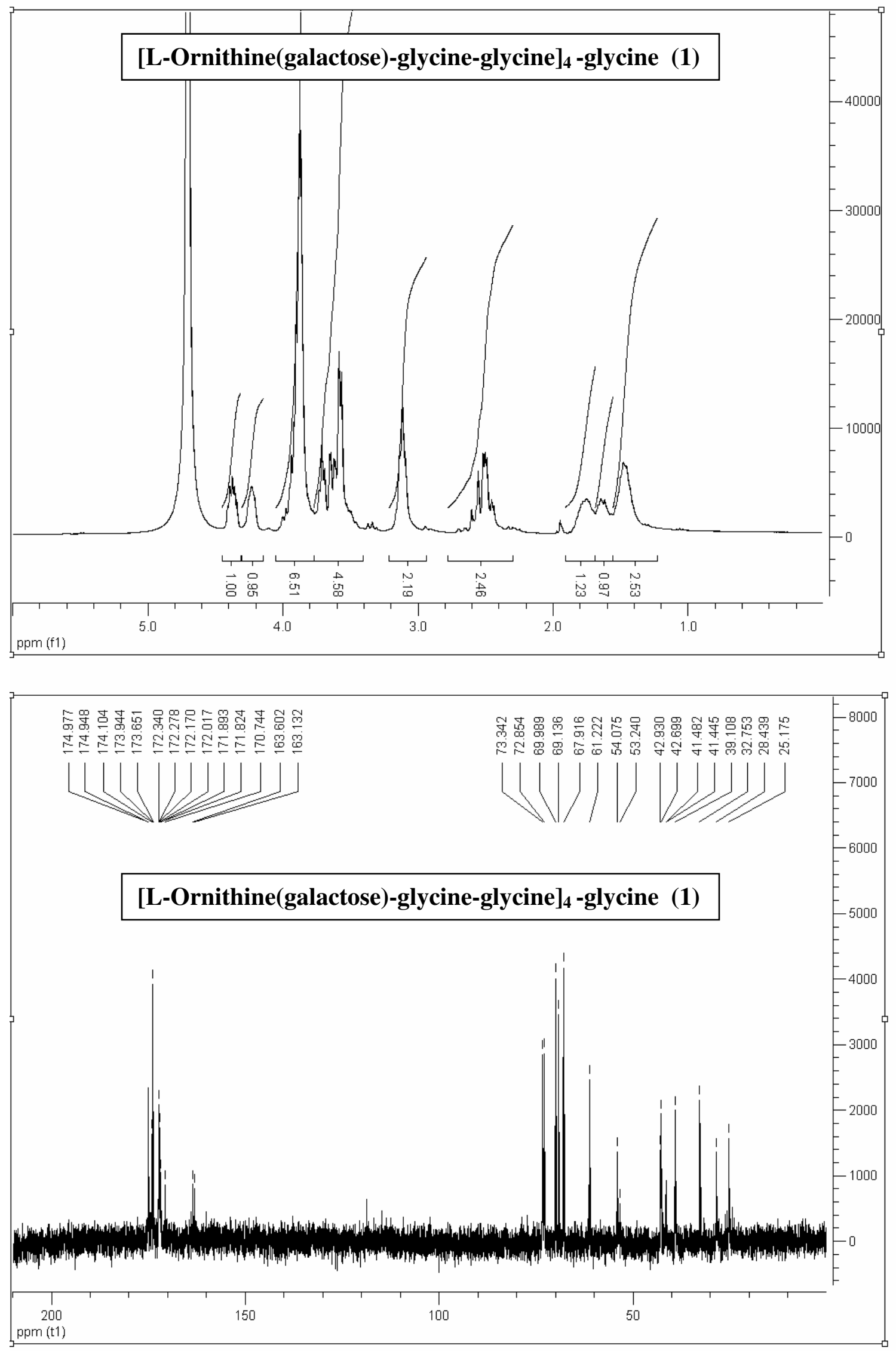


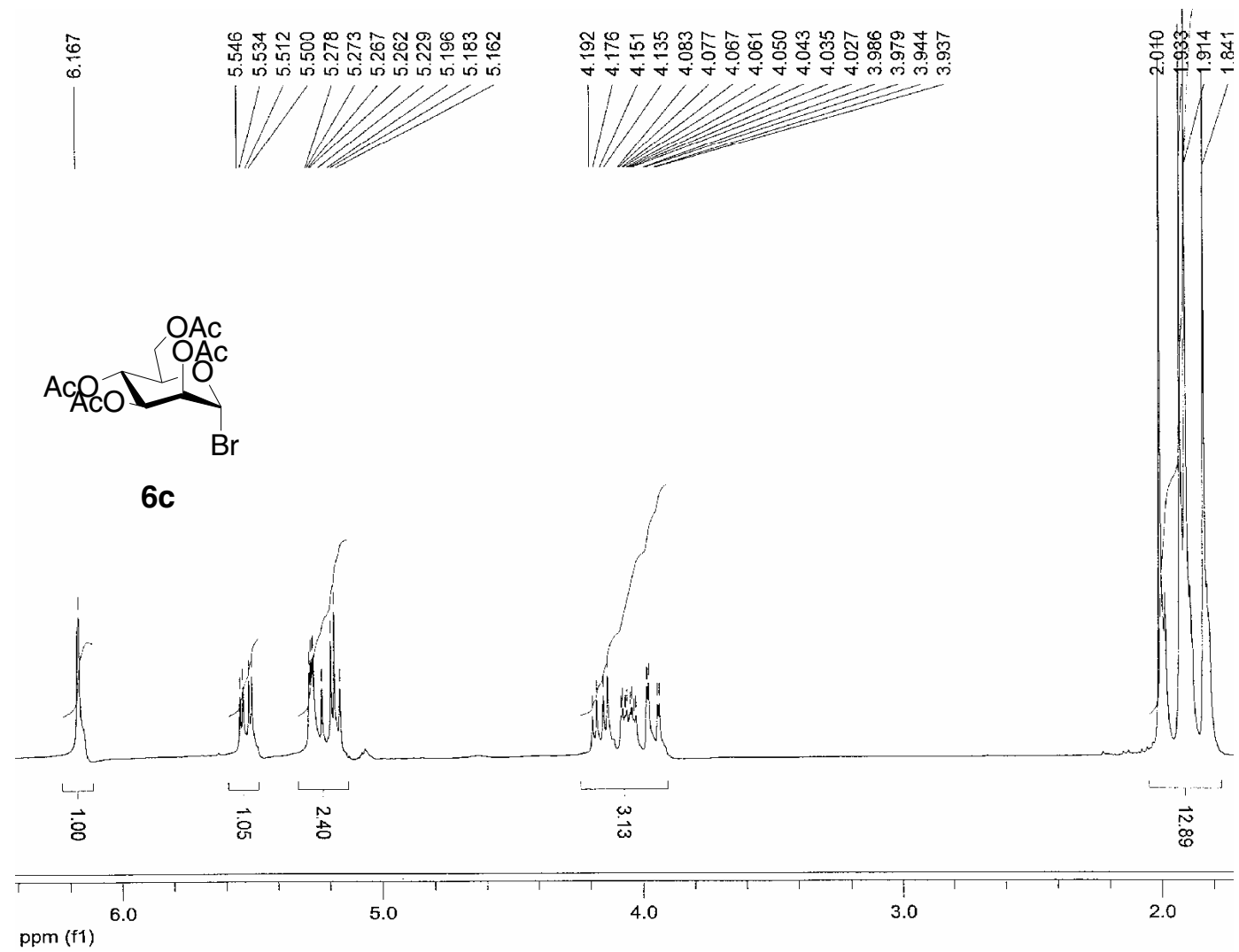

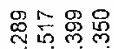

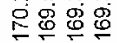

$1 / 1$

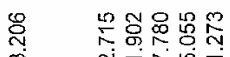

ณ N

$1 / 11$

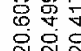
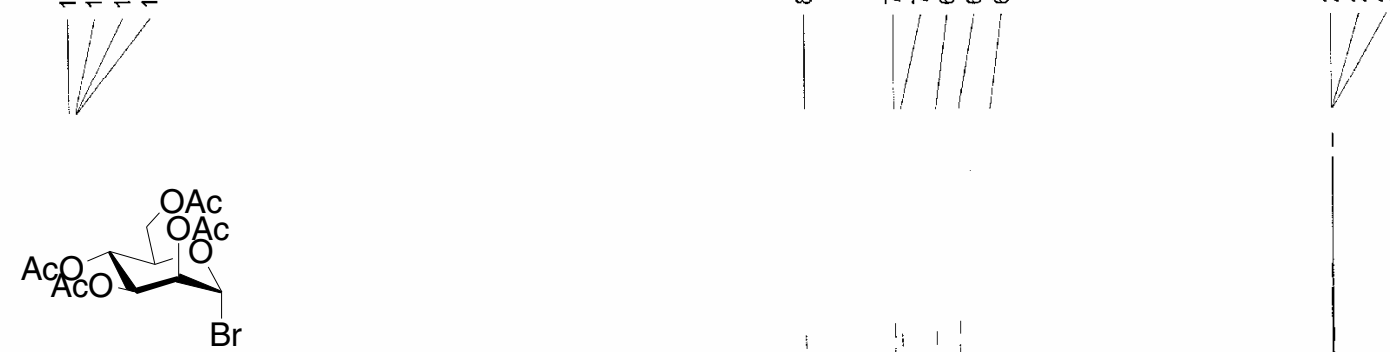

$6 c$
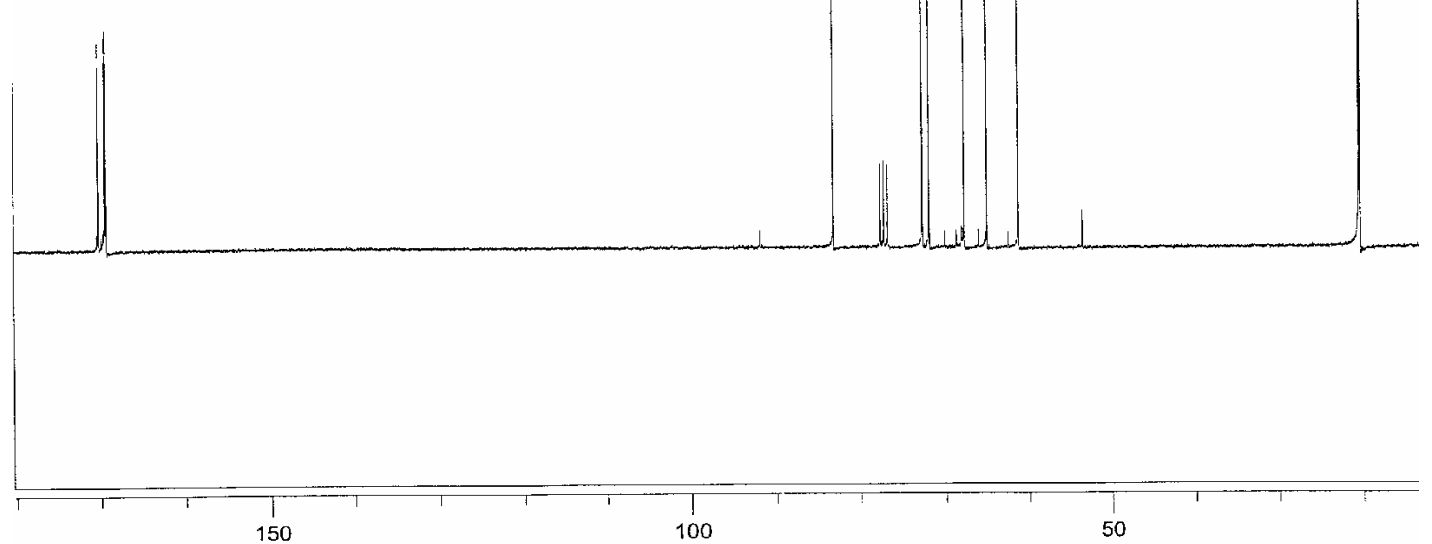

ppm (f1) 

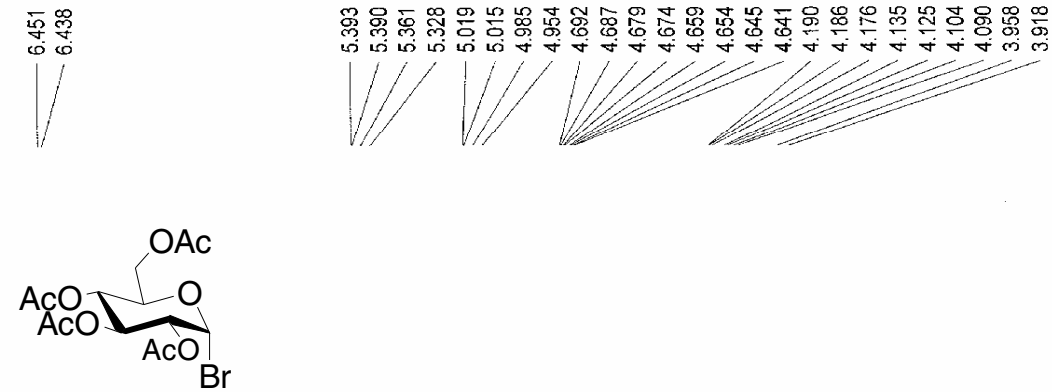

$6 b$
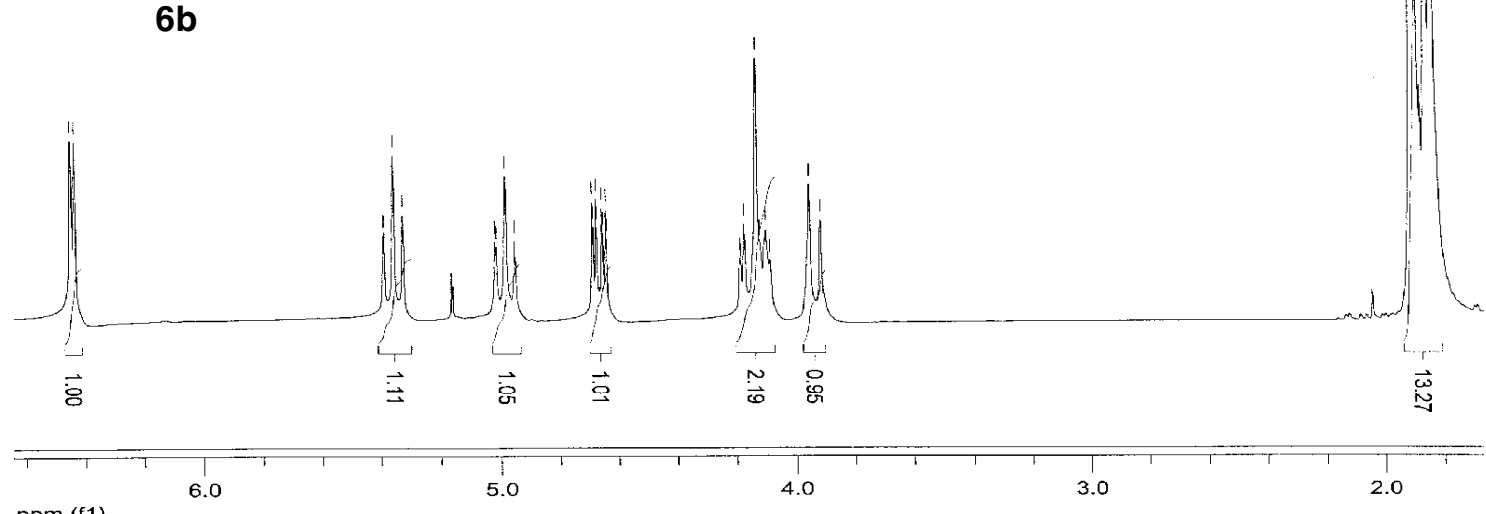

ppm (f1)

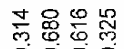

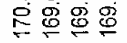

H

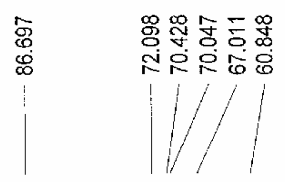

每罂㝵

ํํํำ

I/

$\underbrace{\mathrm{OAc}}_{\mathrm{AcO}}$

$6 b$

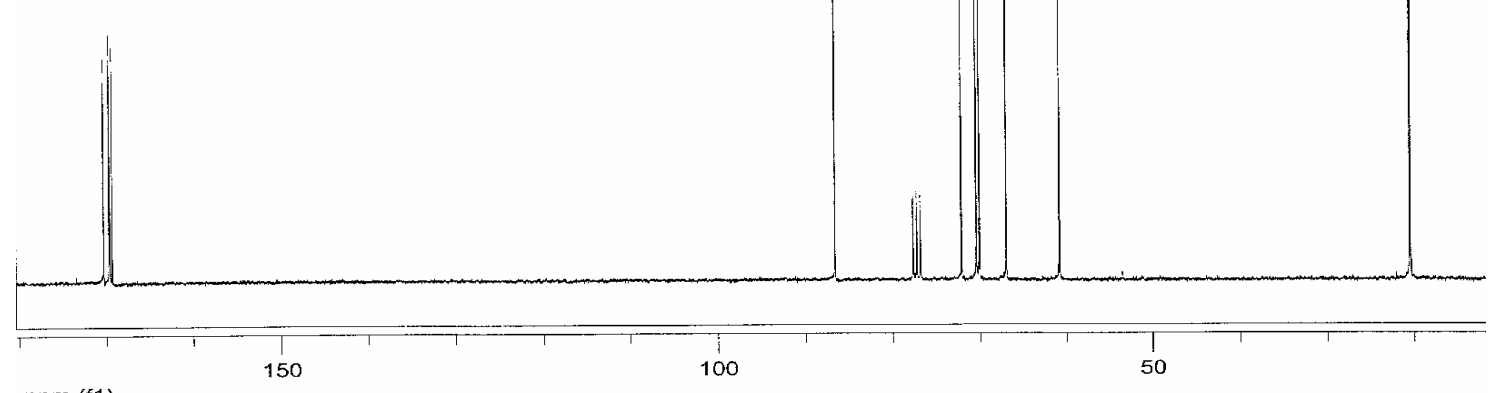

ppm (f1) 

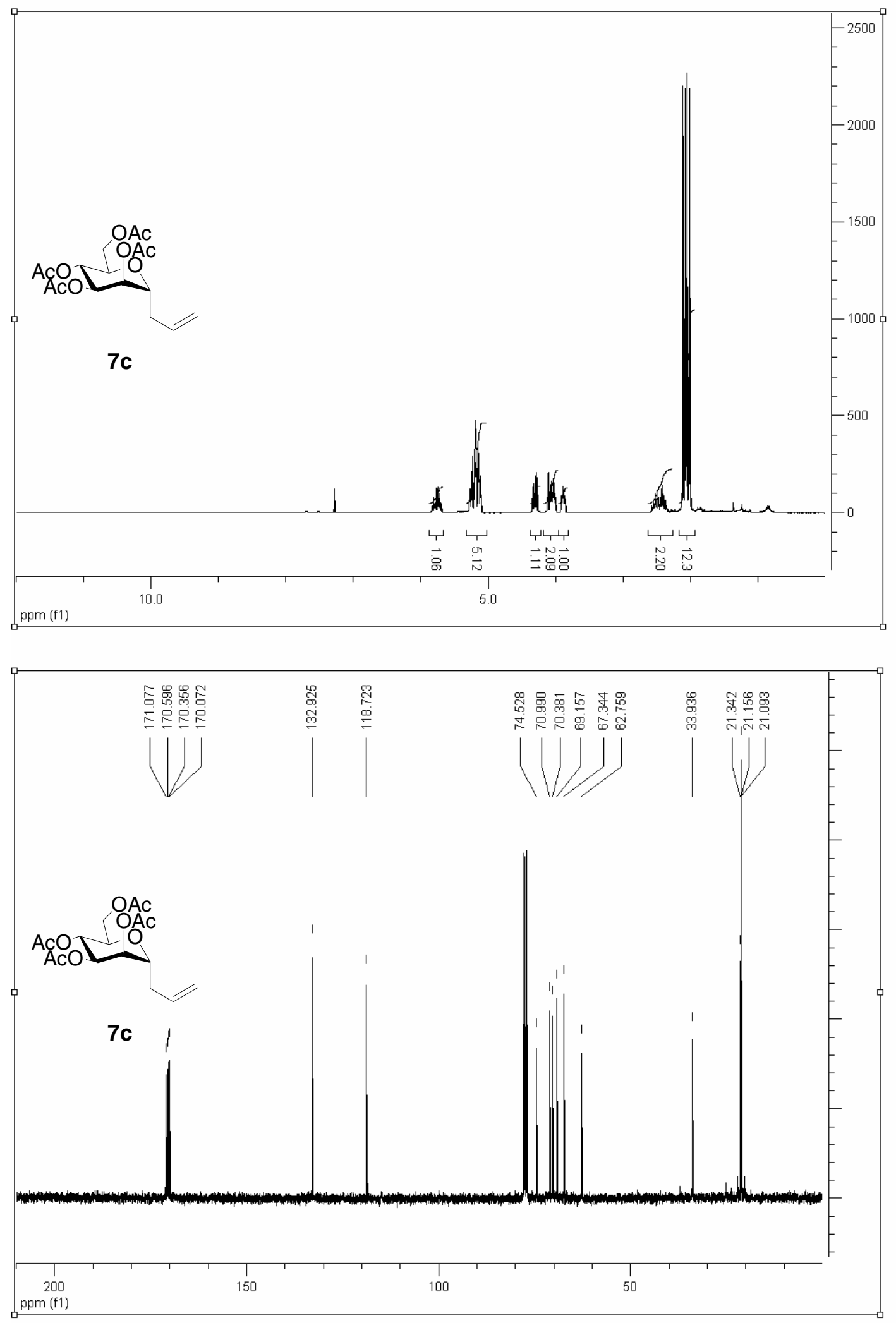

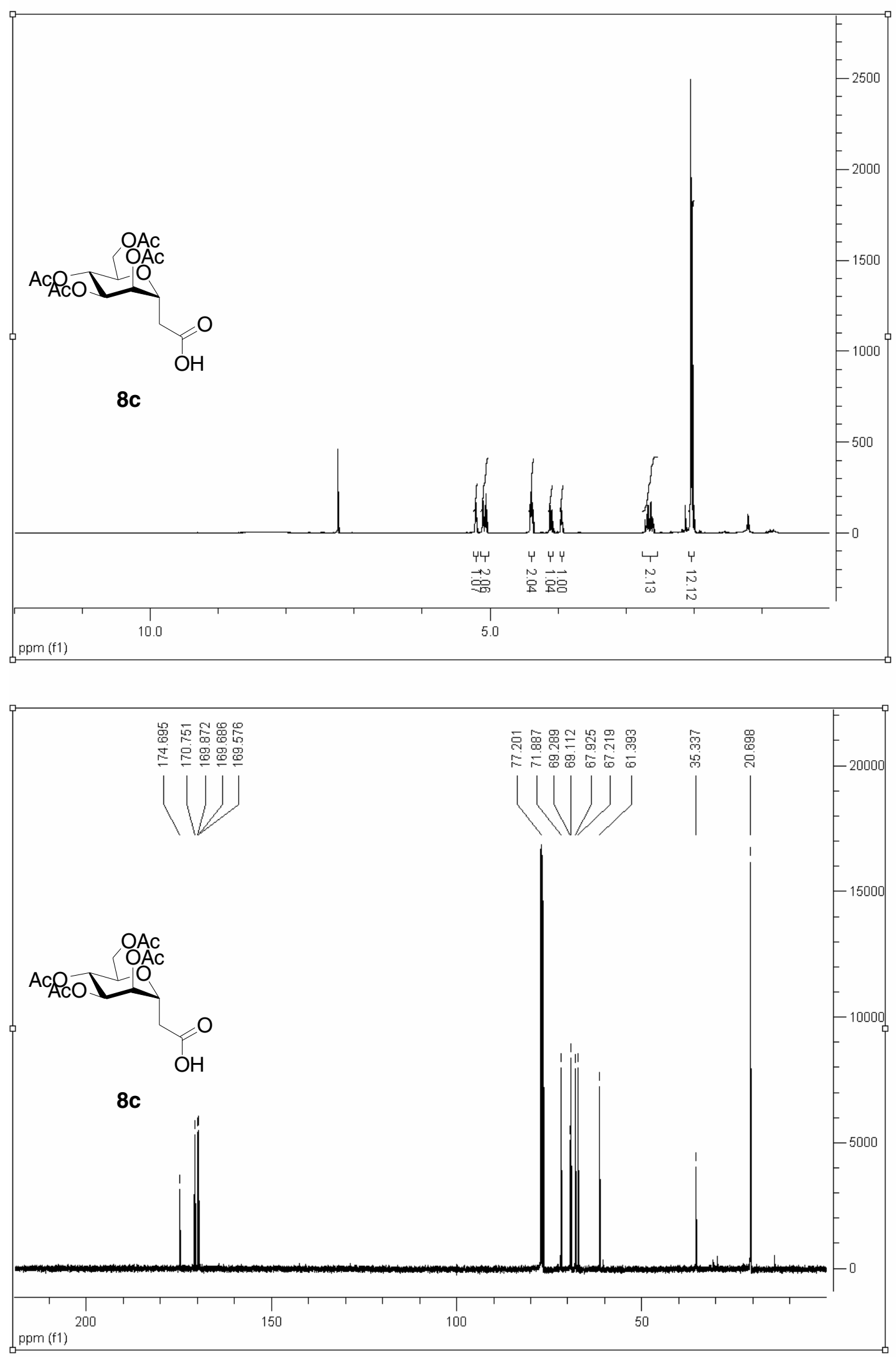

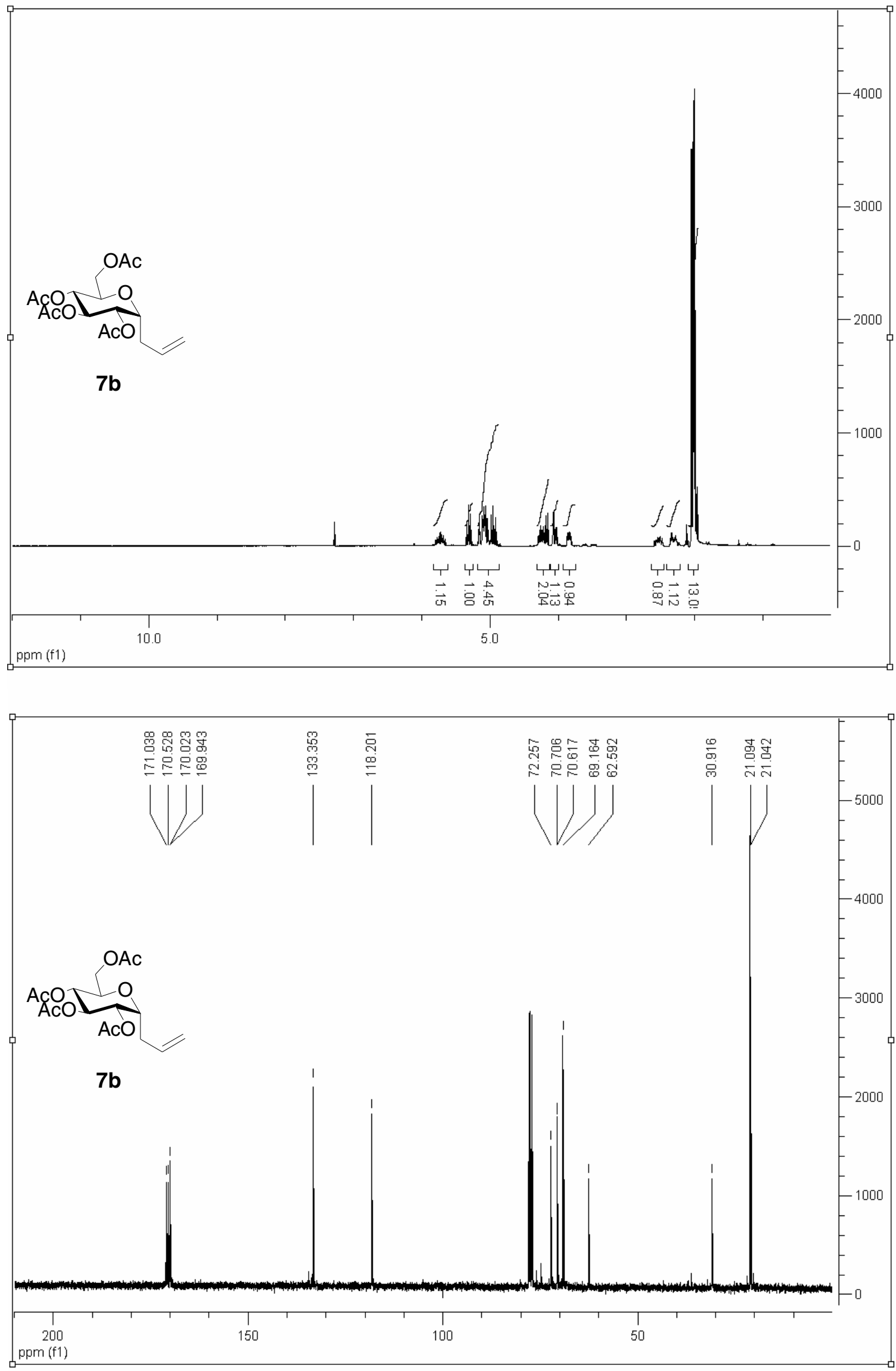

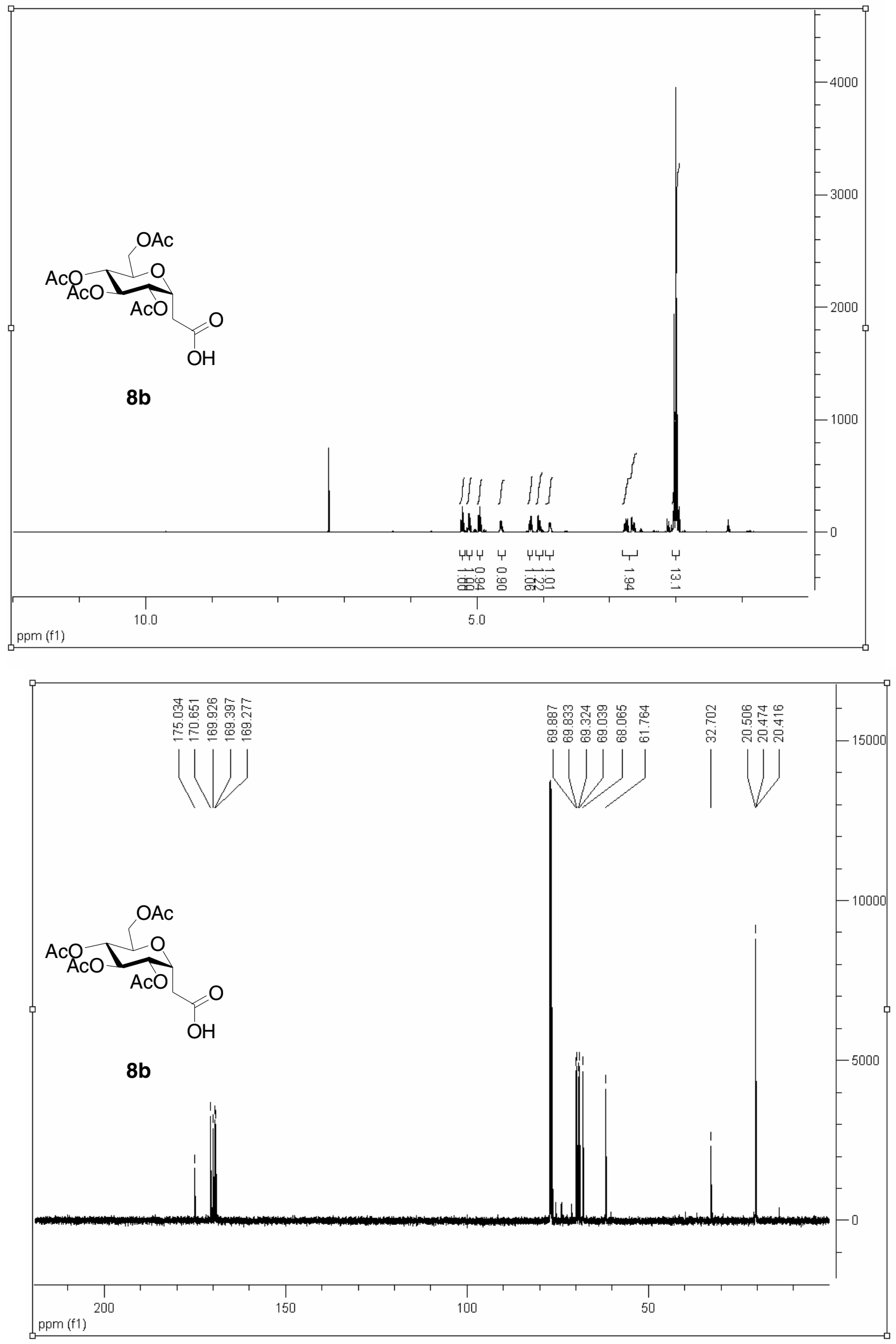

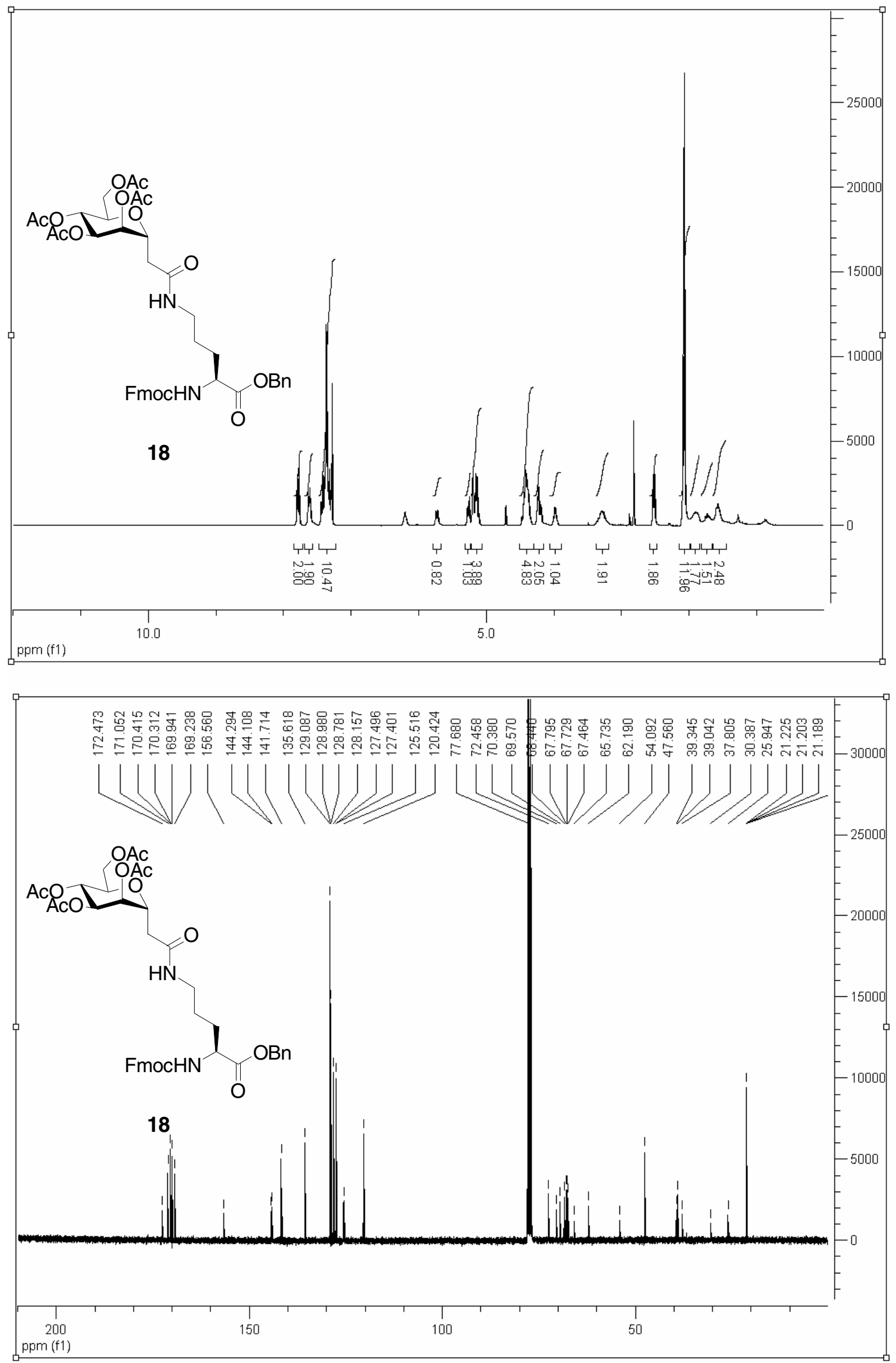

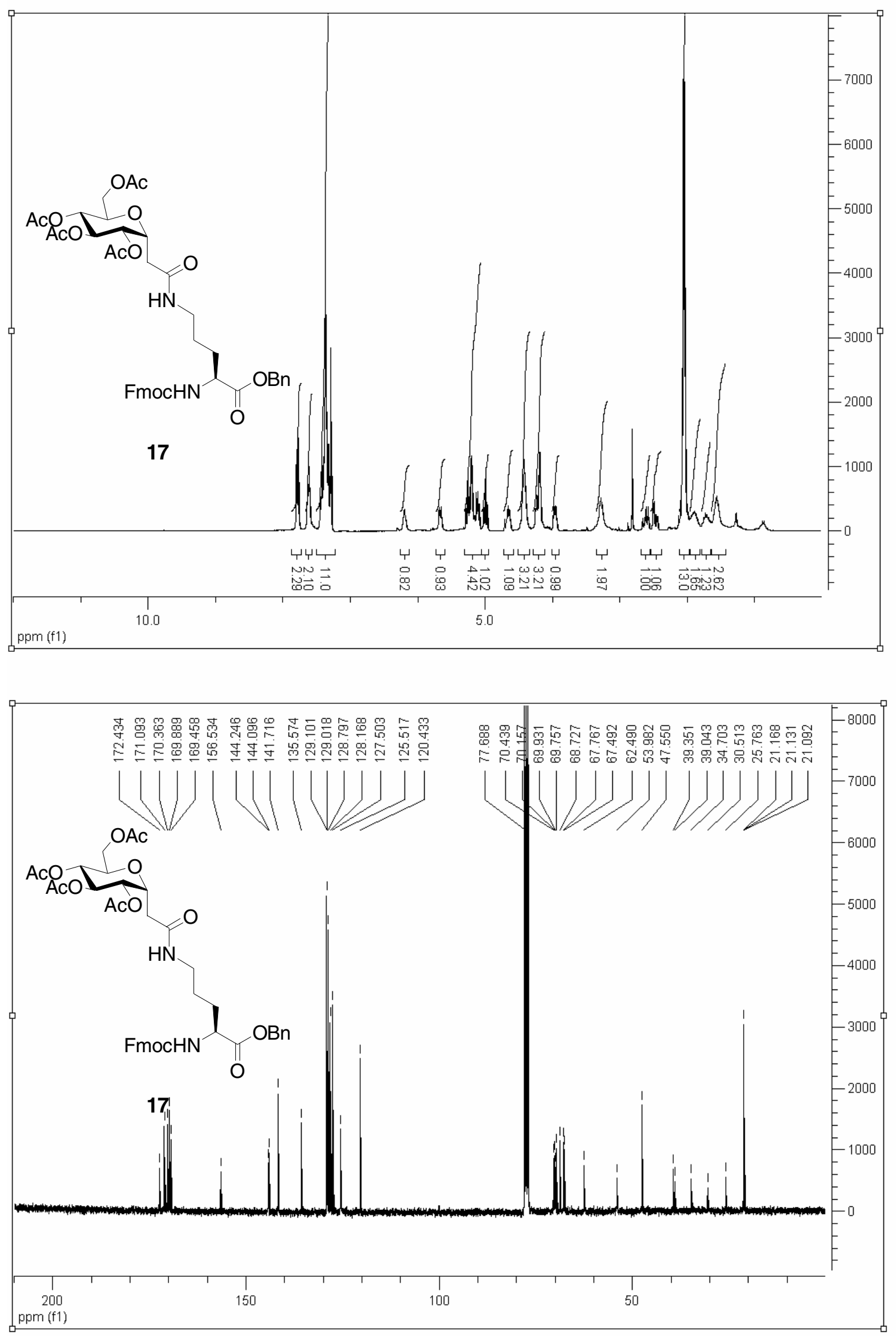

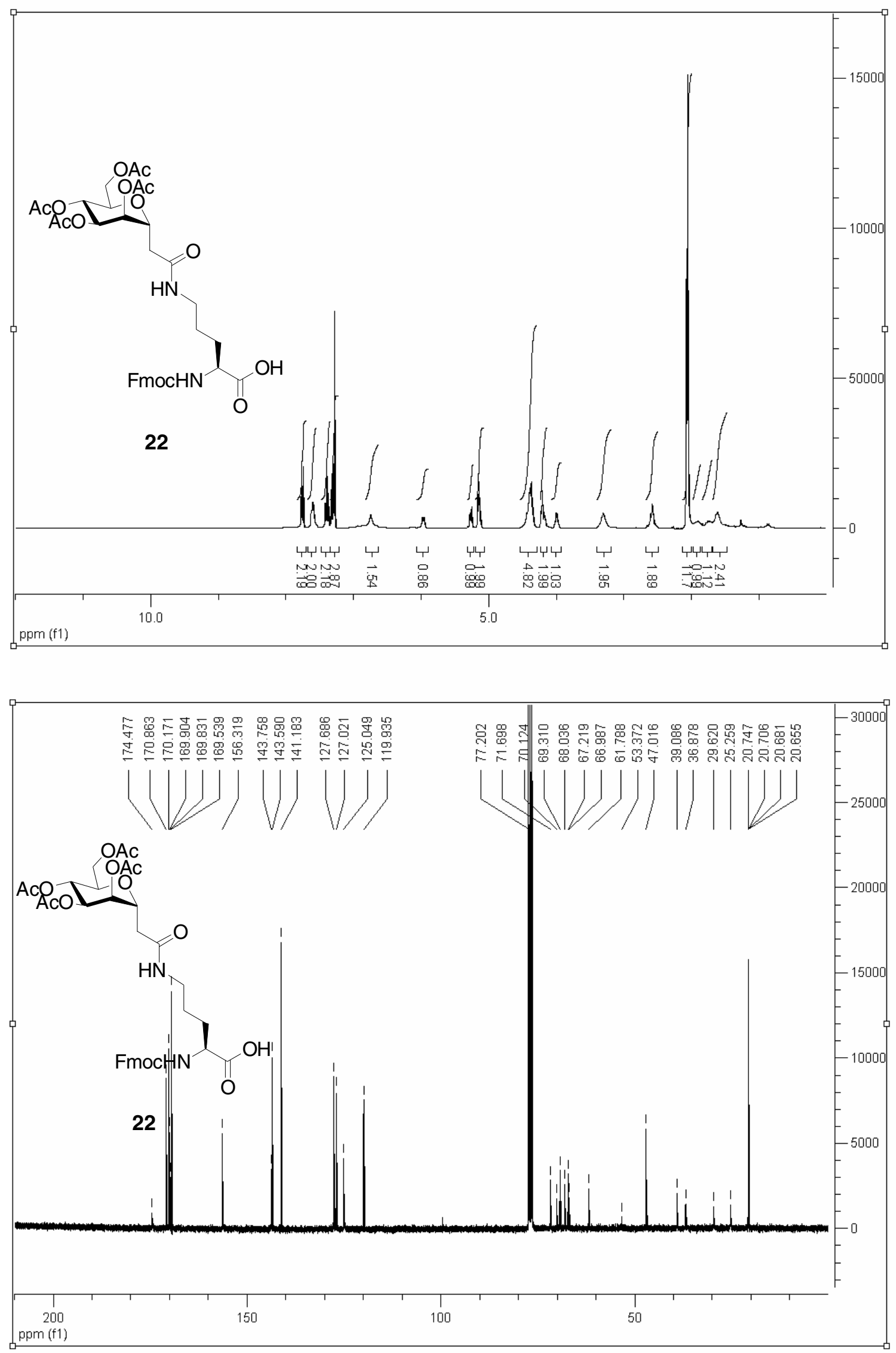

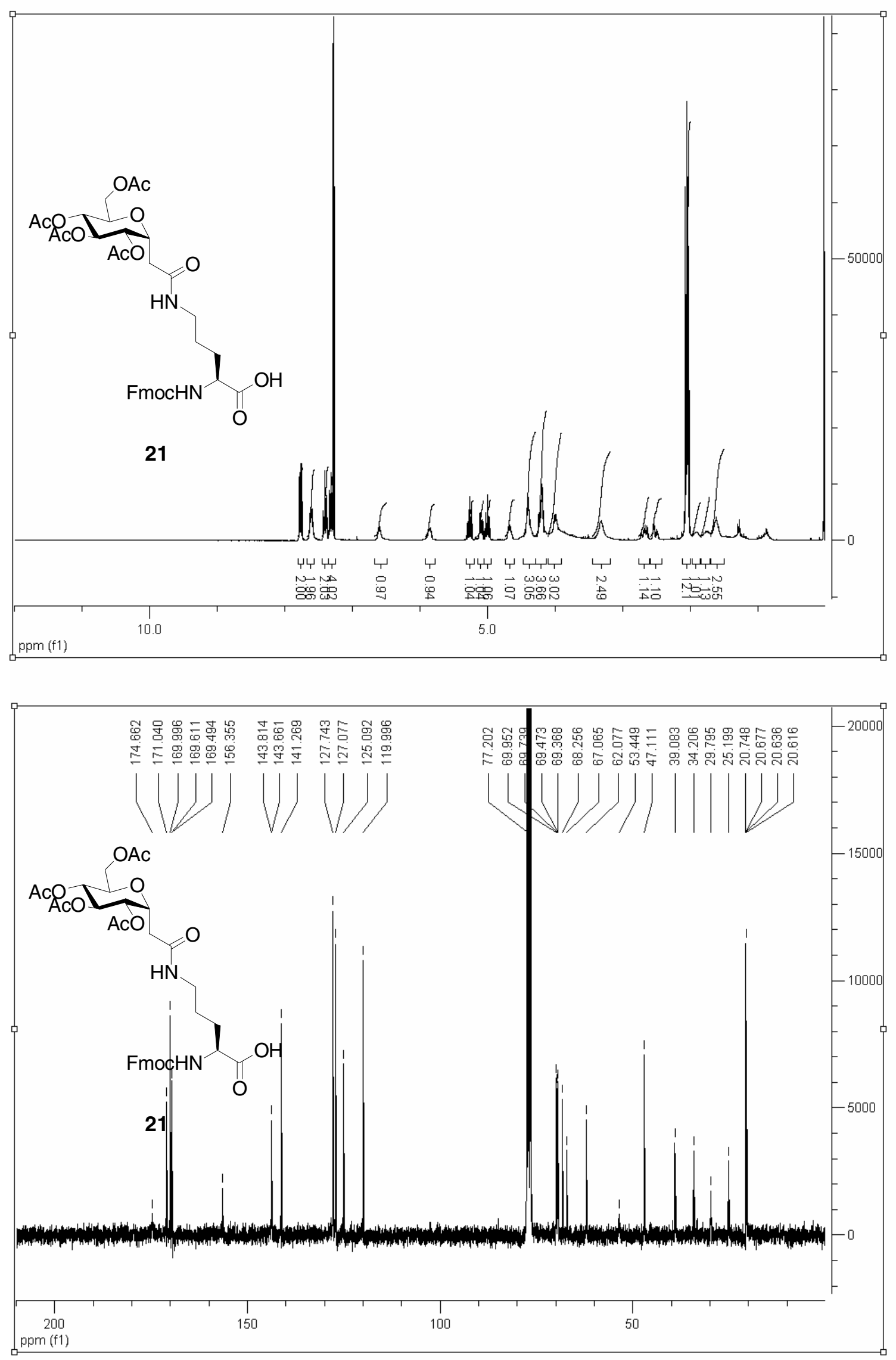


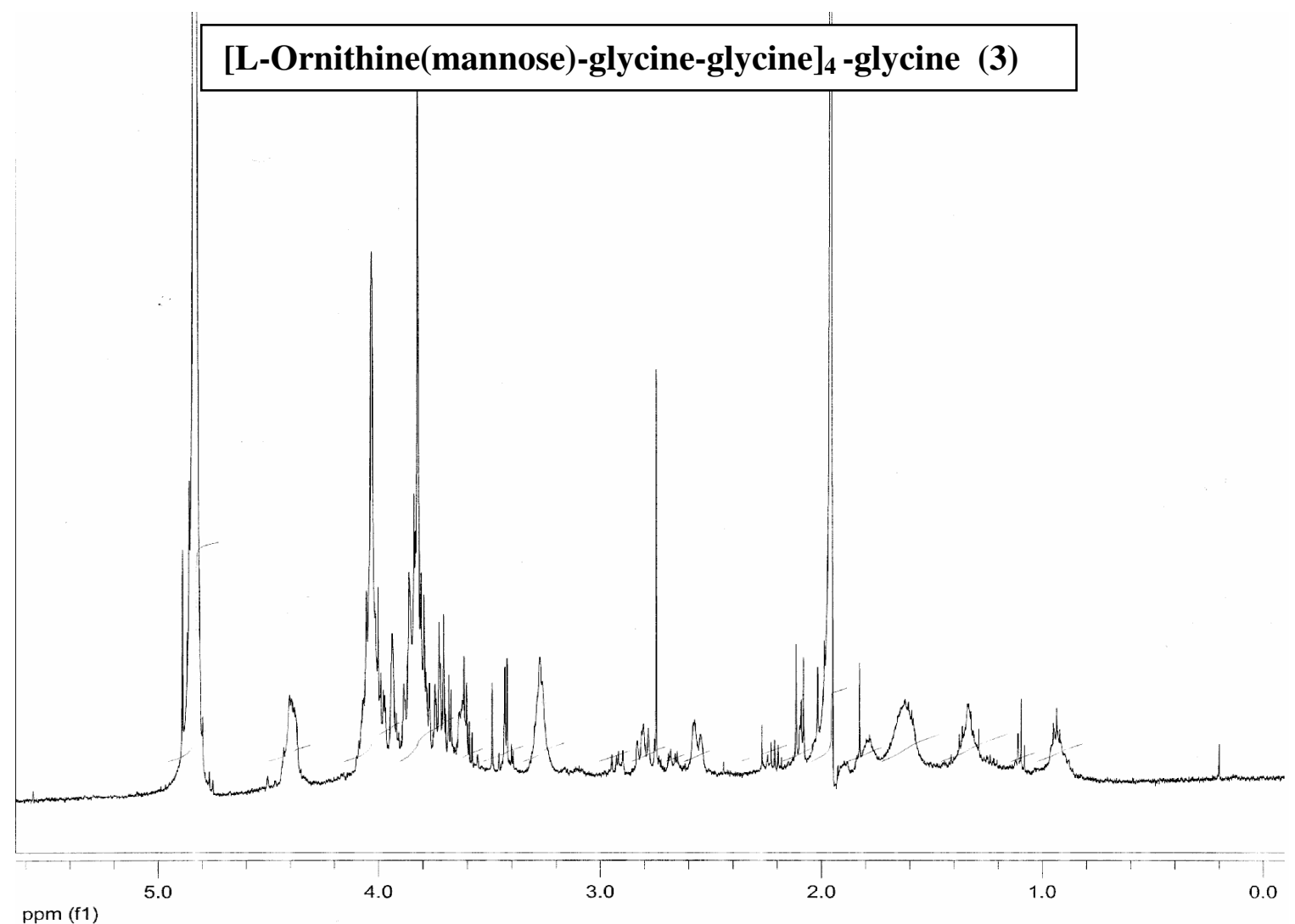

言

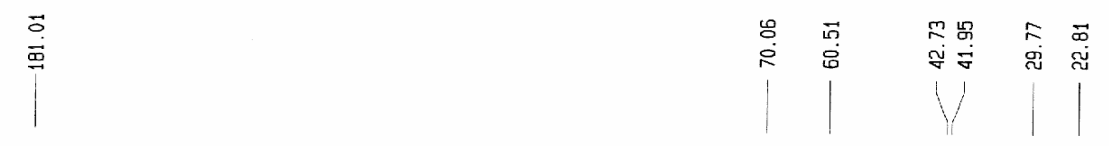

[L-Ornithine(mannose)-glycine-glycine $]_{4}$-glycine (3)

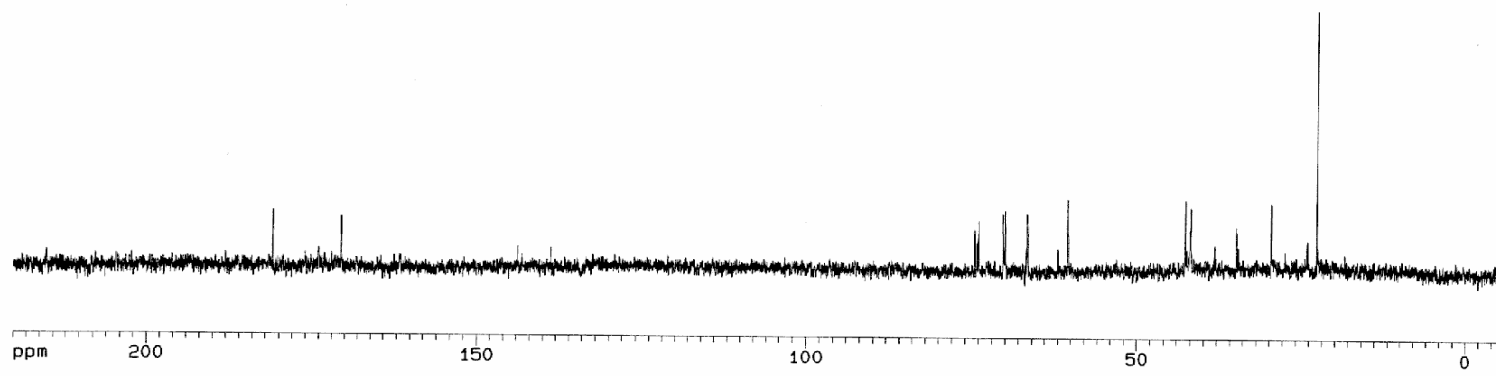




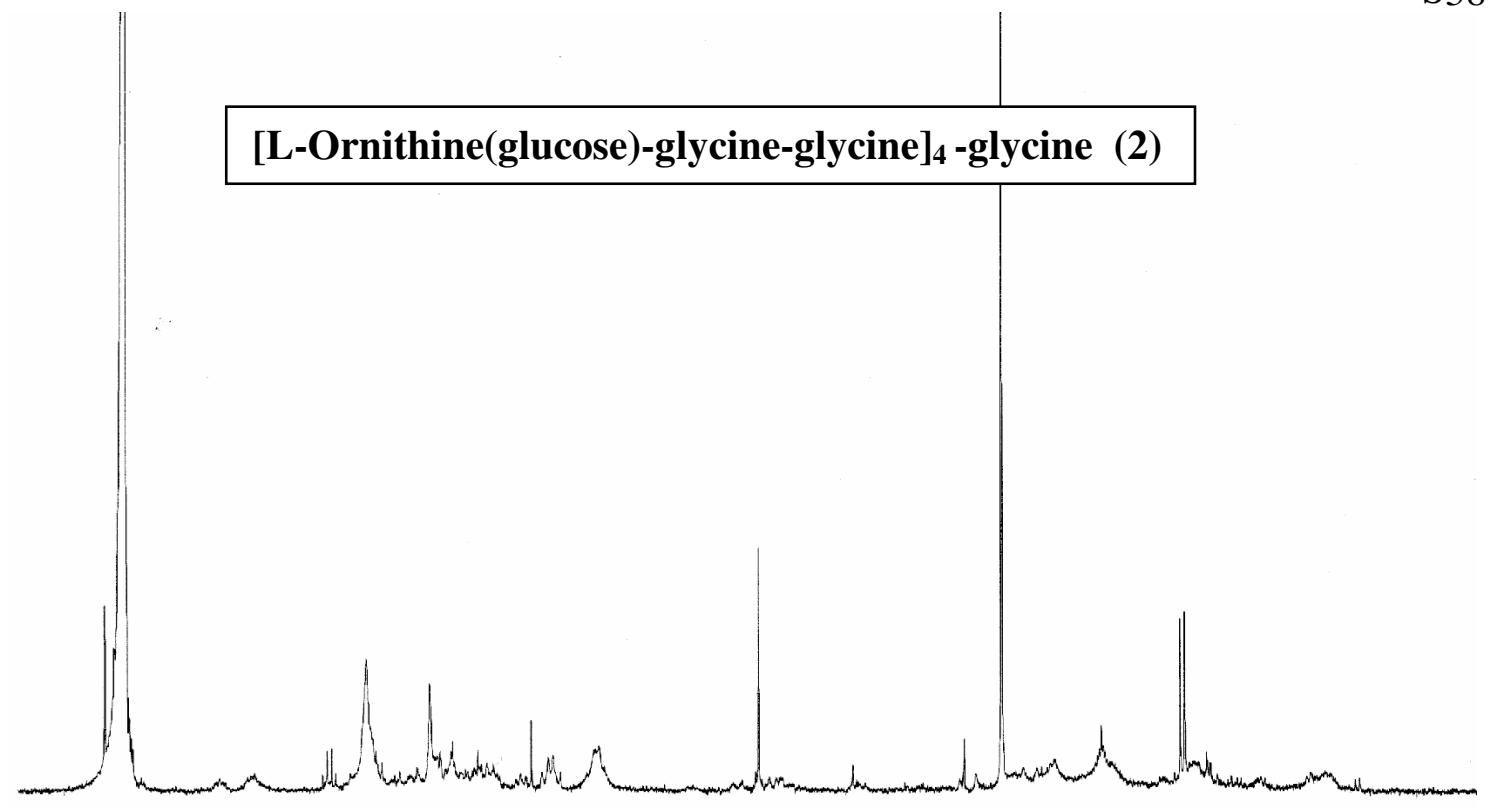

$$
\text { ppm }
$$

[L-Ornithine(glucose)-glycine-glycine $]_{4}$-glycine (2)

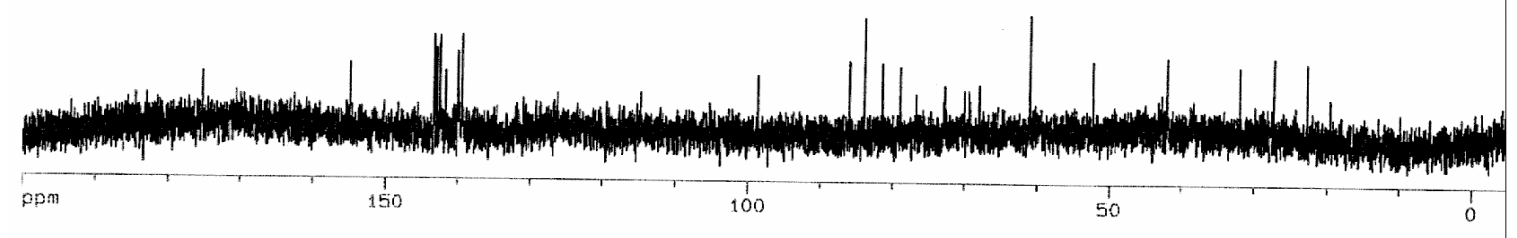



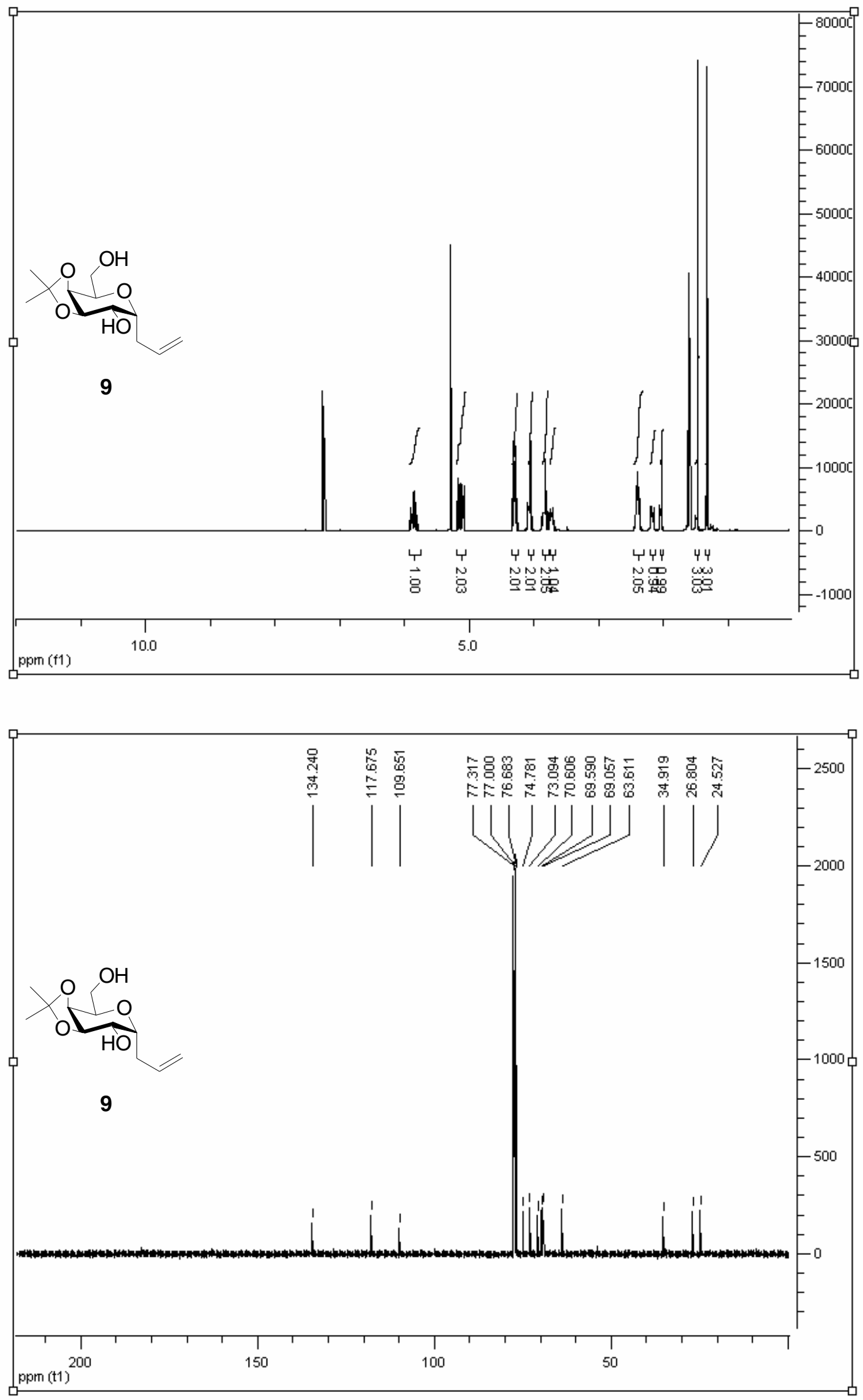

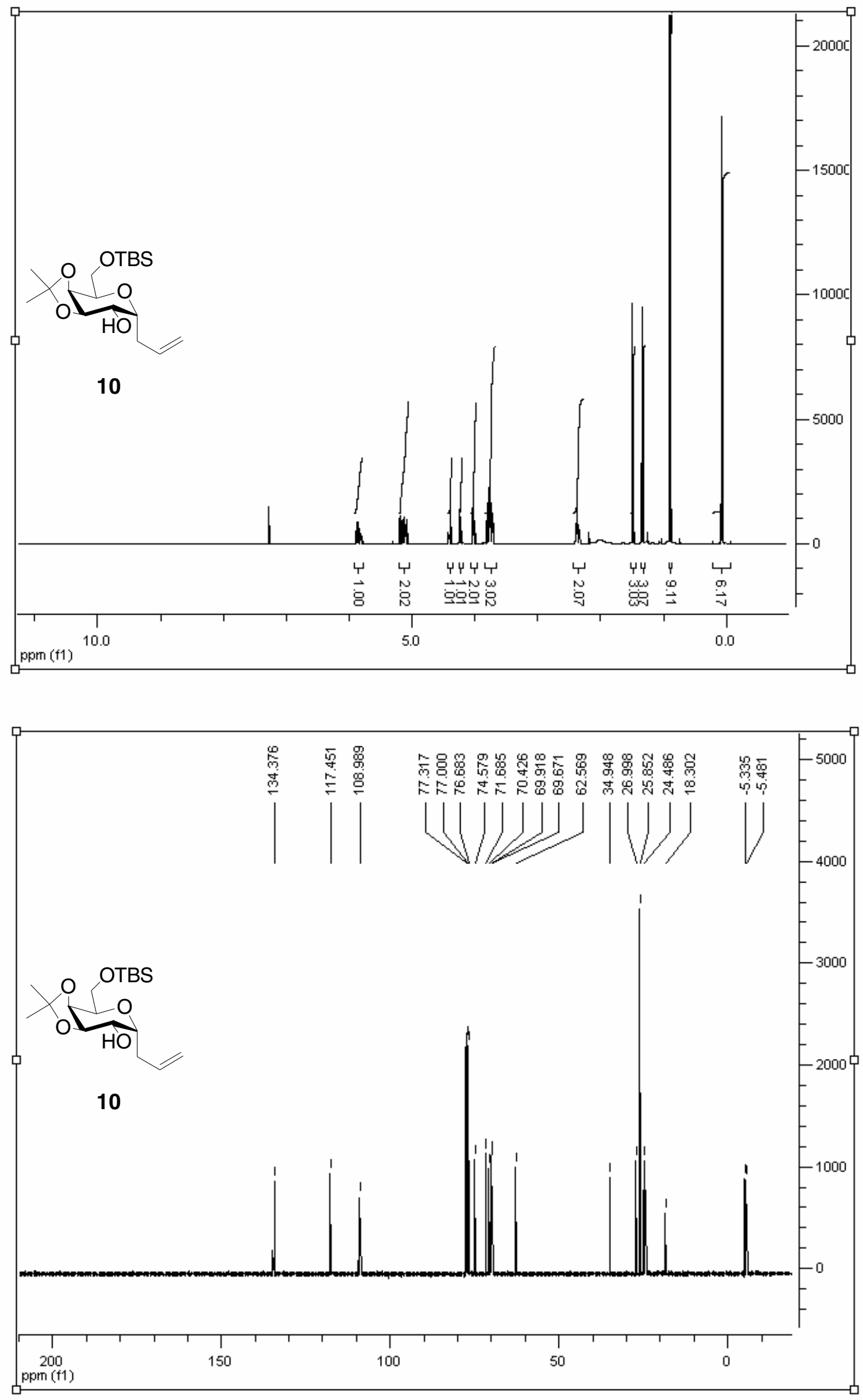

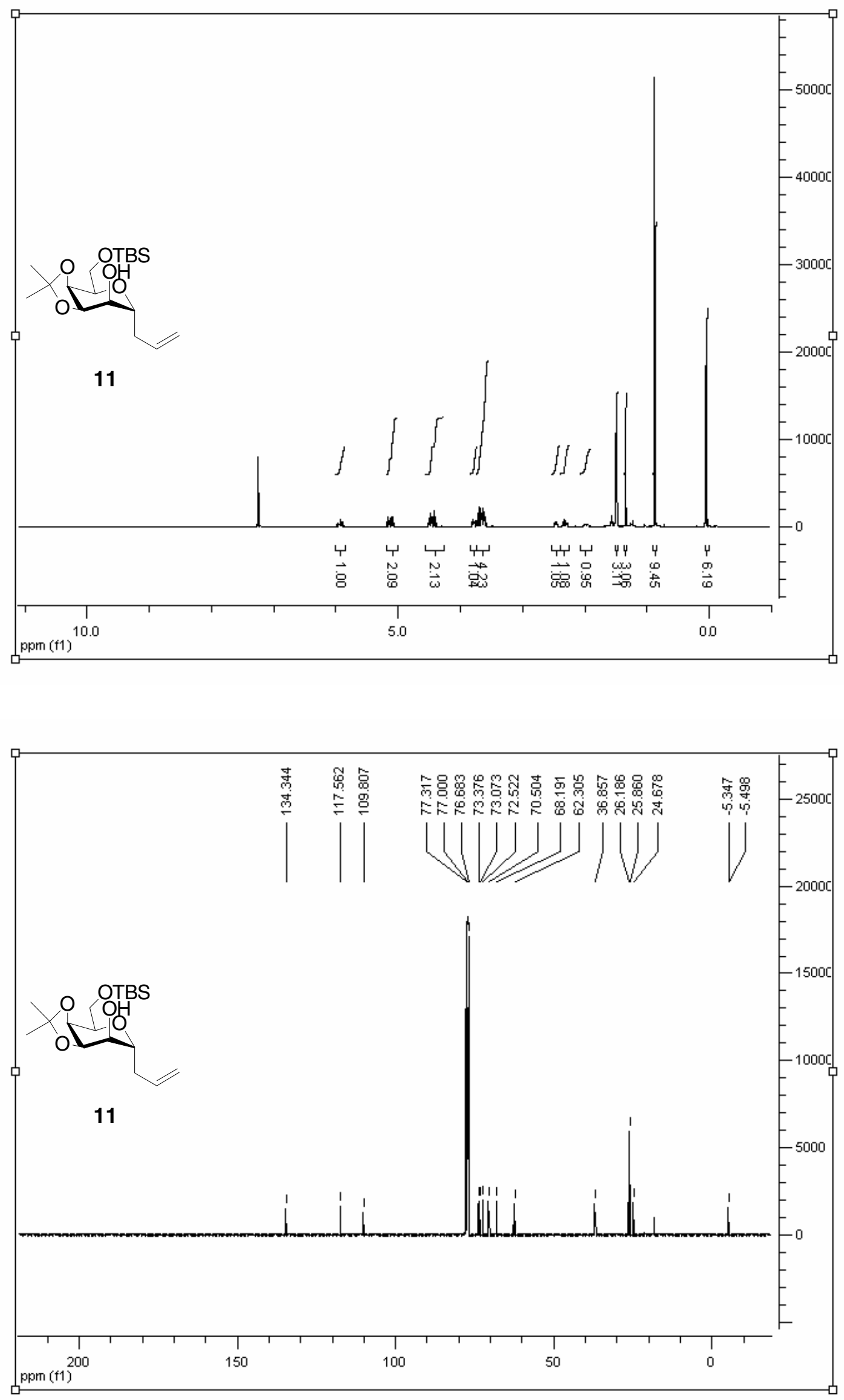

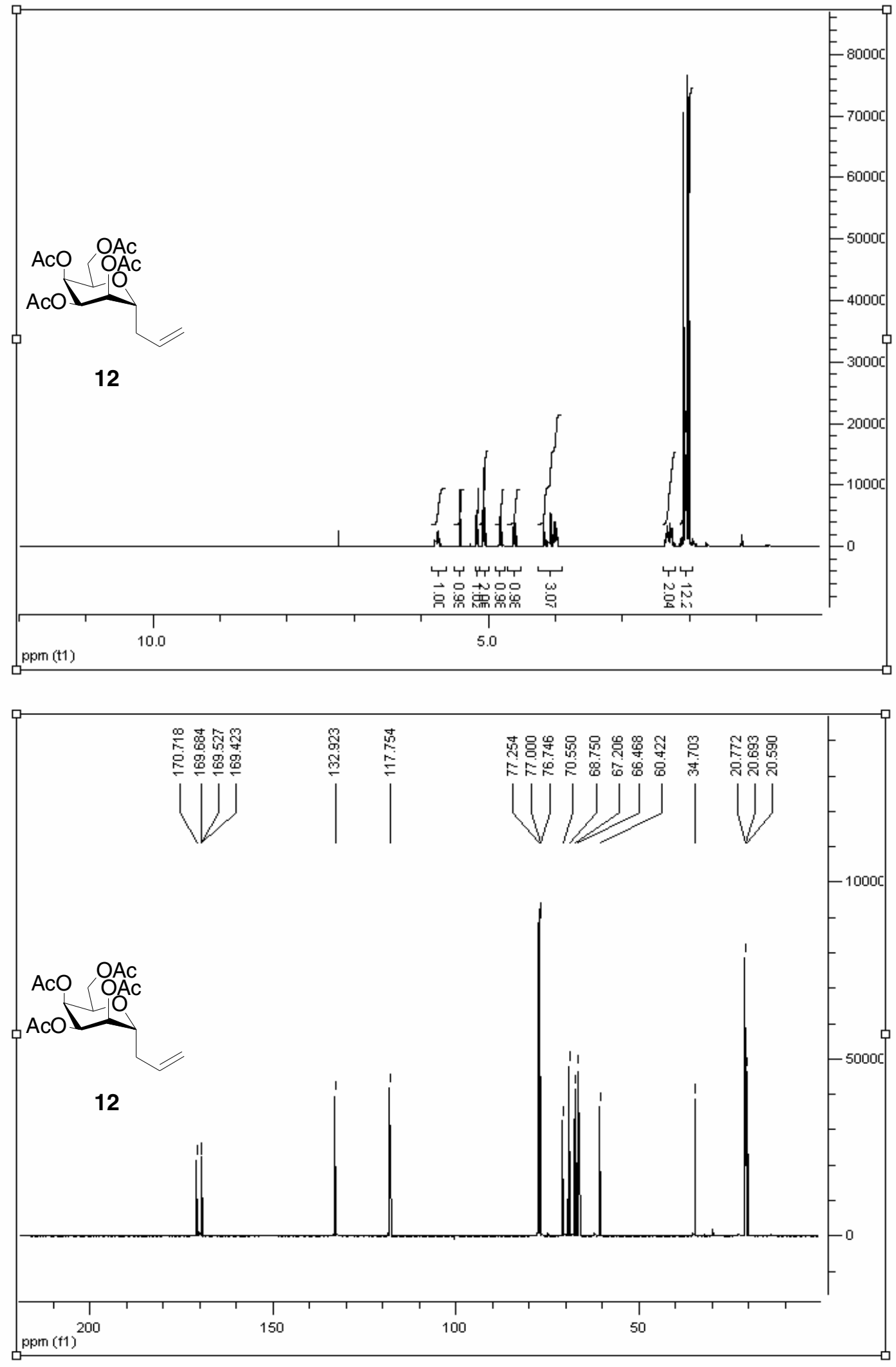

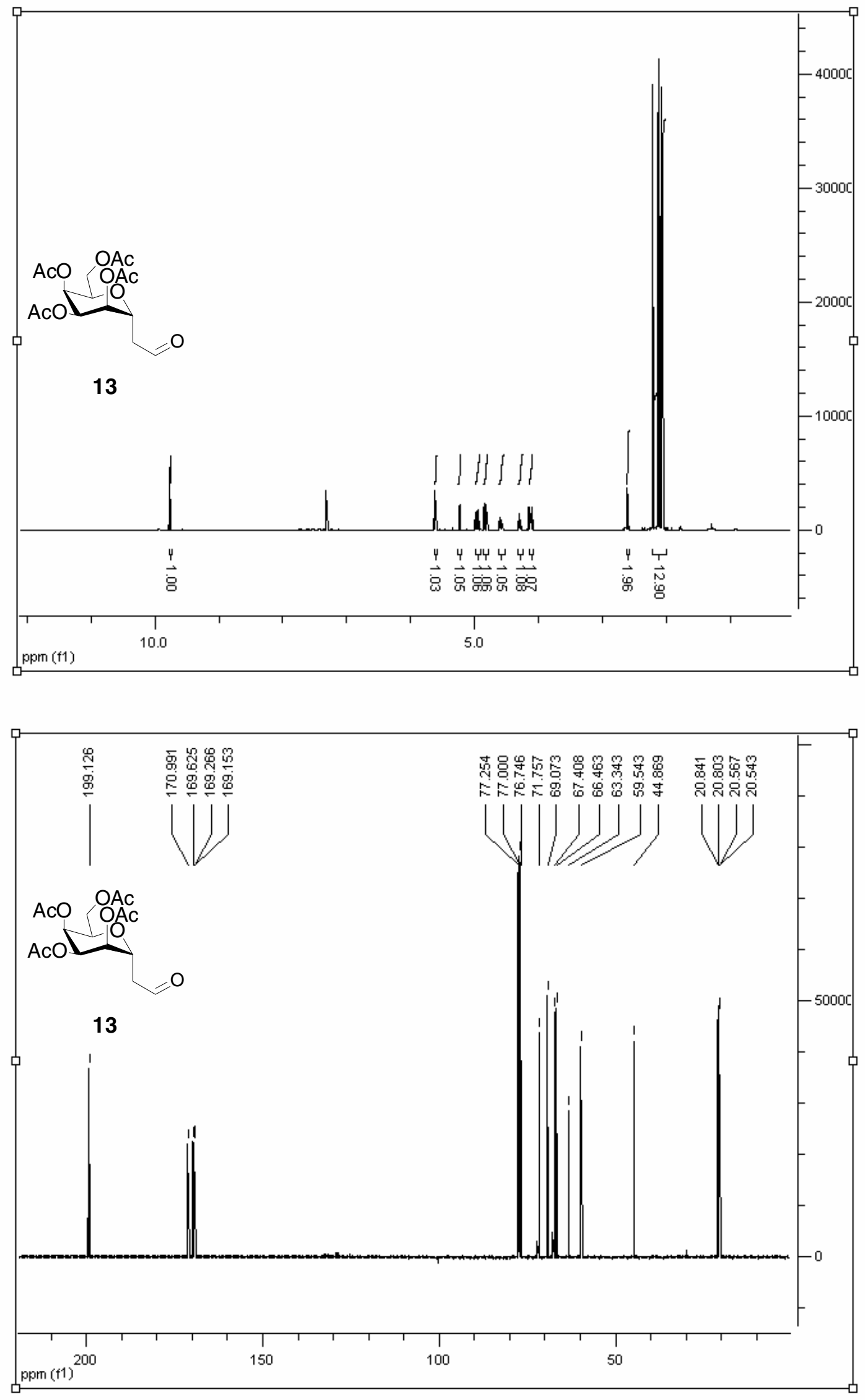

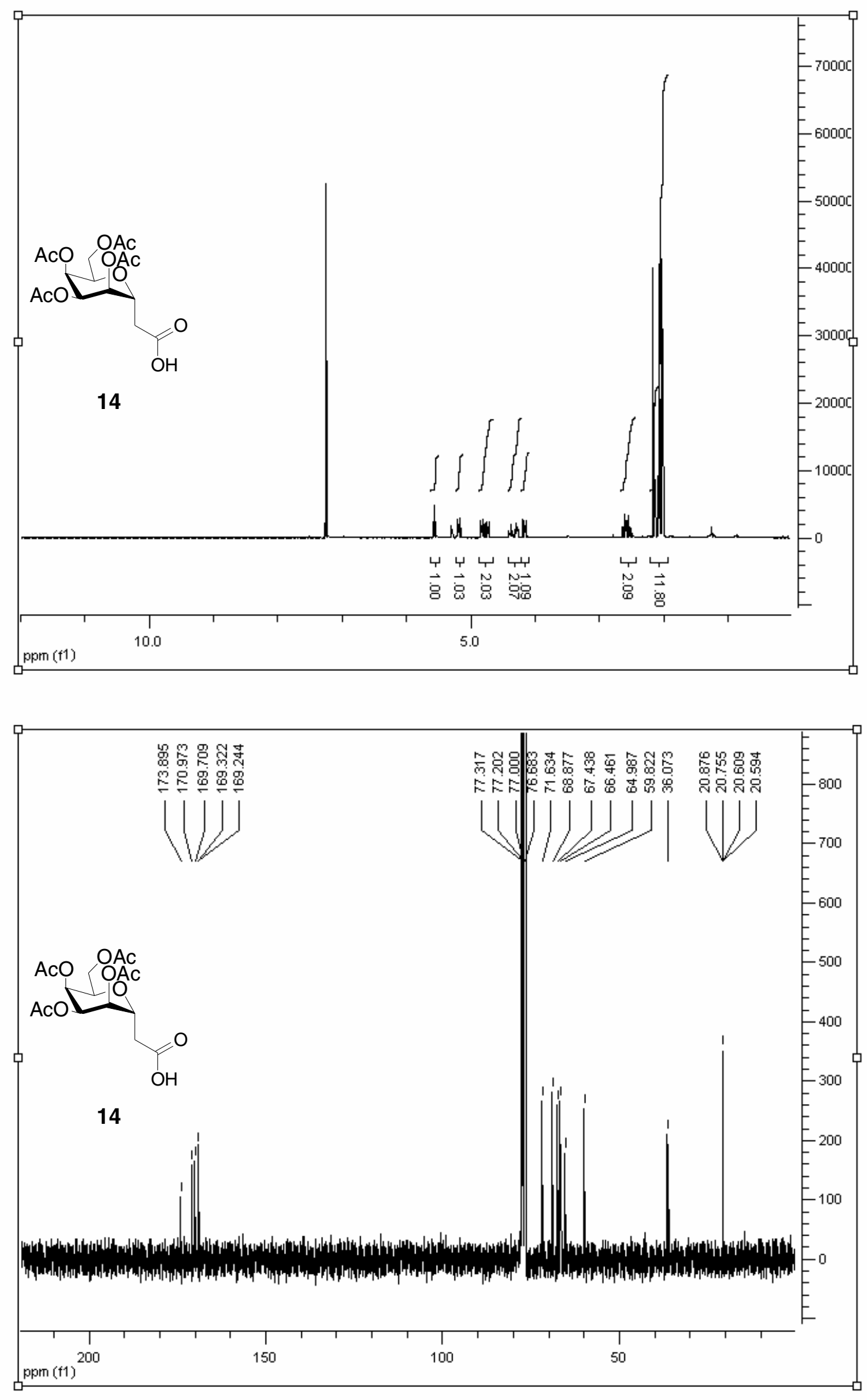

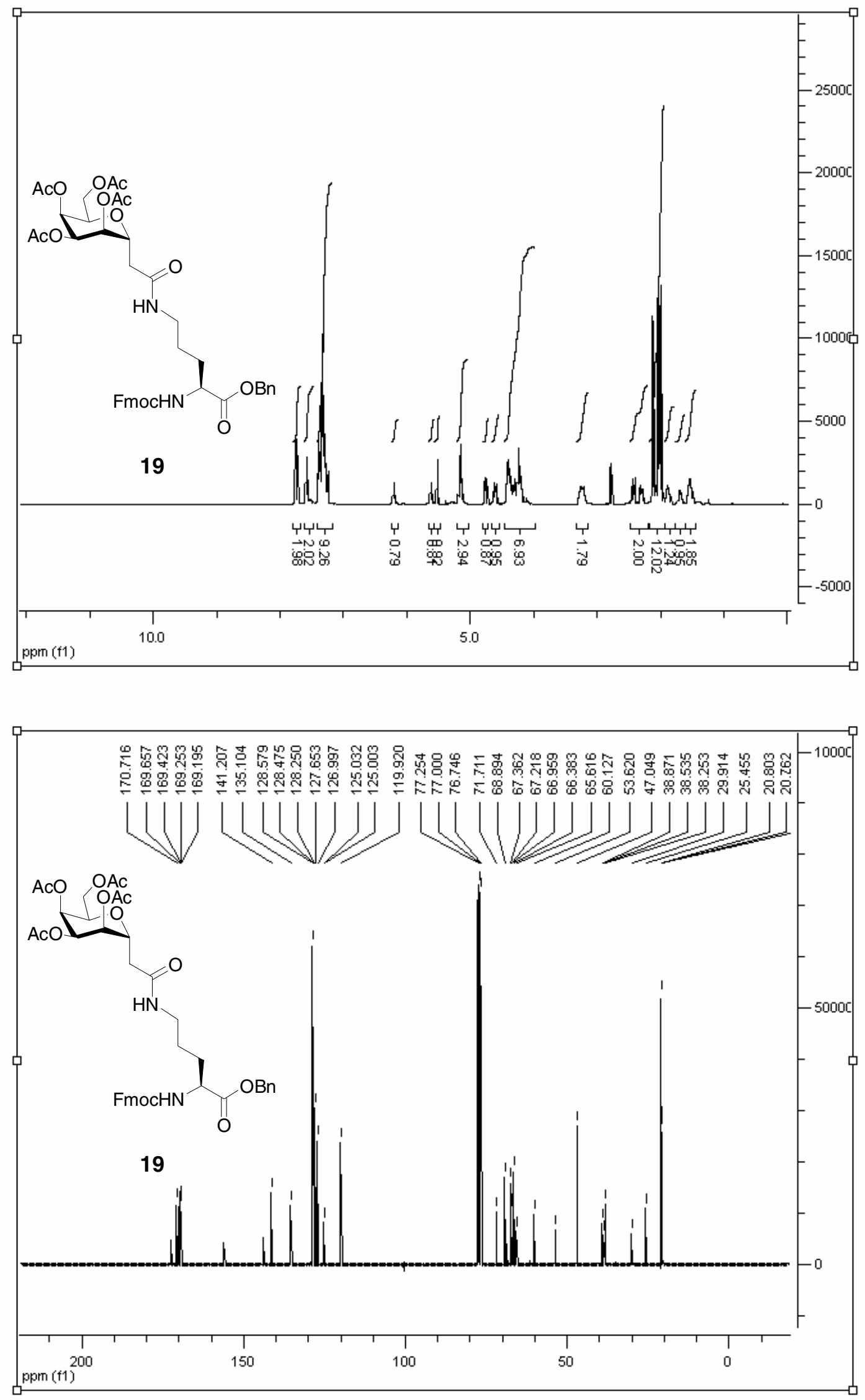

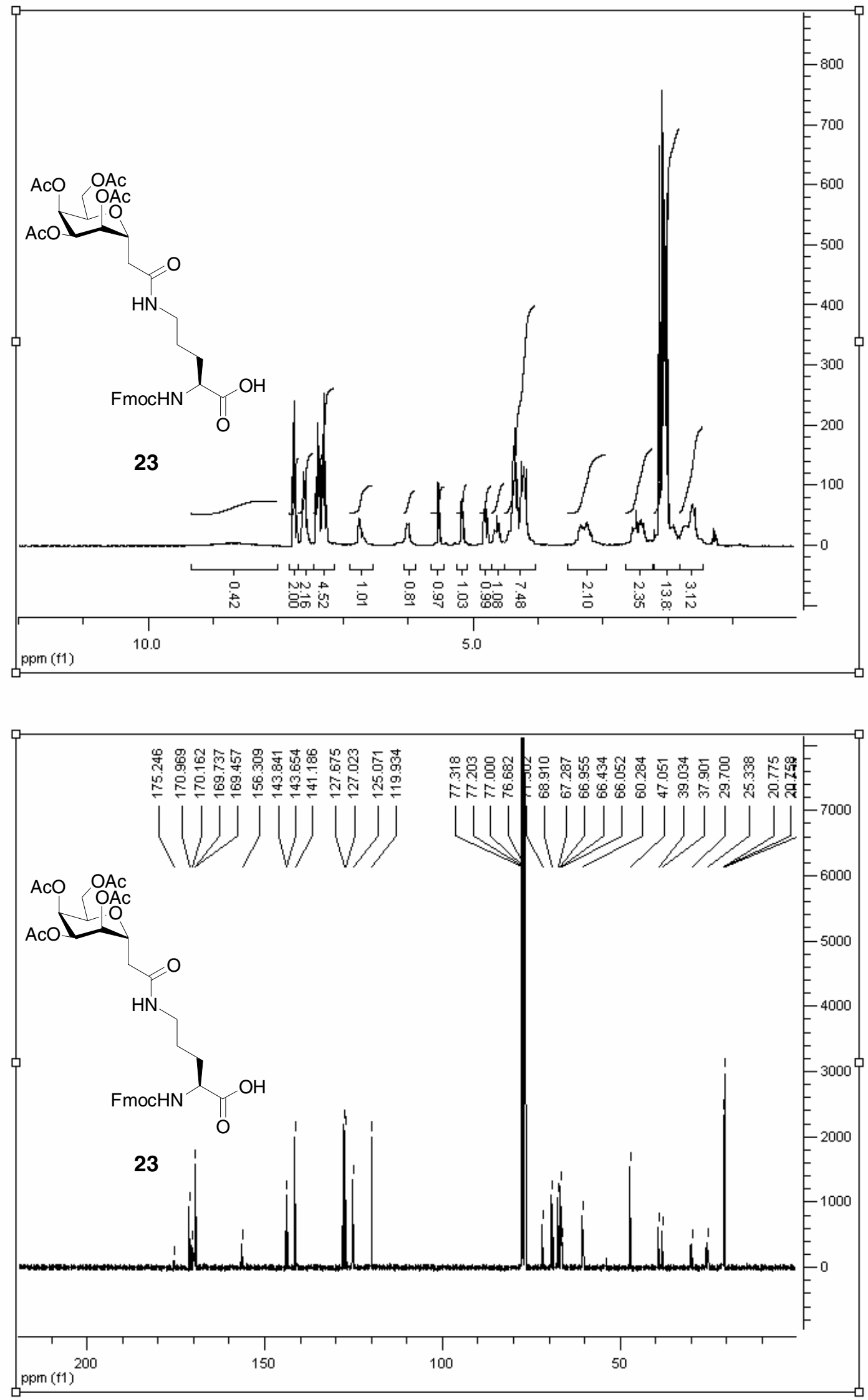

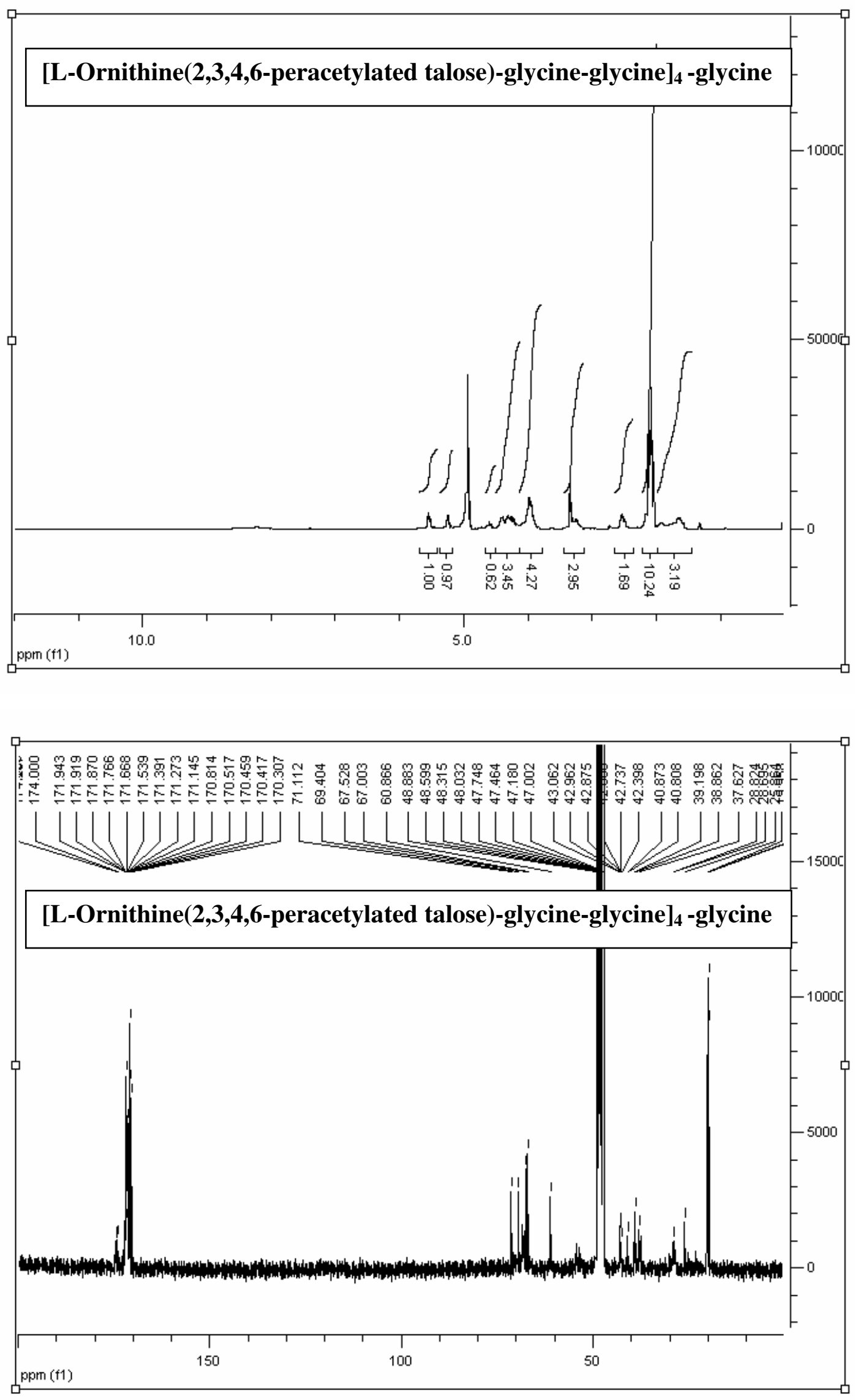

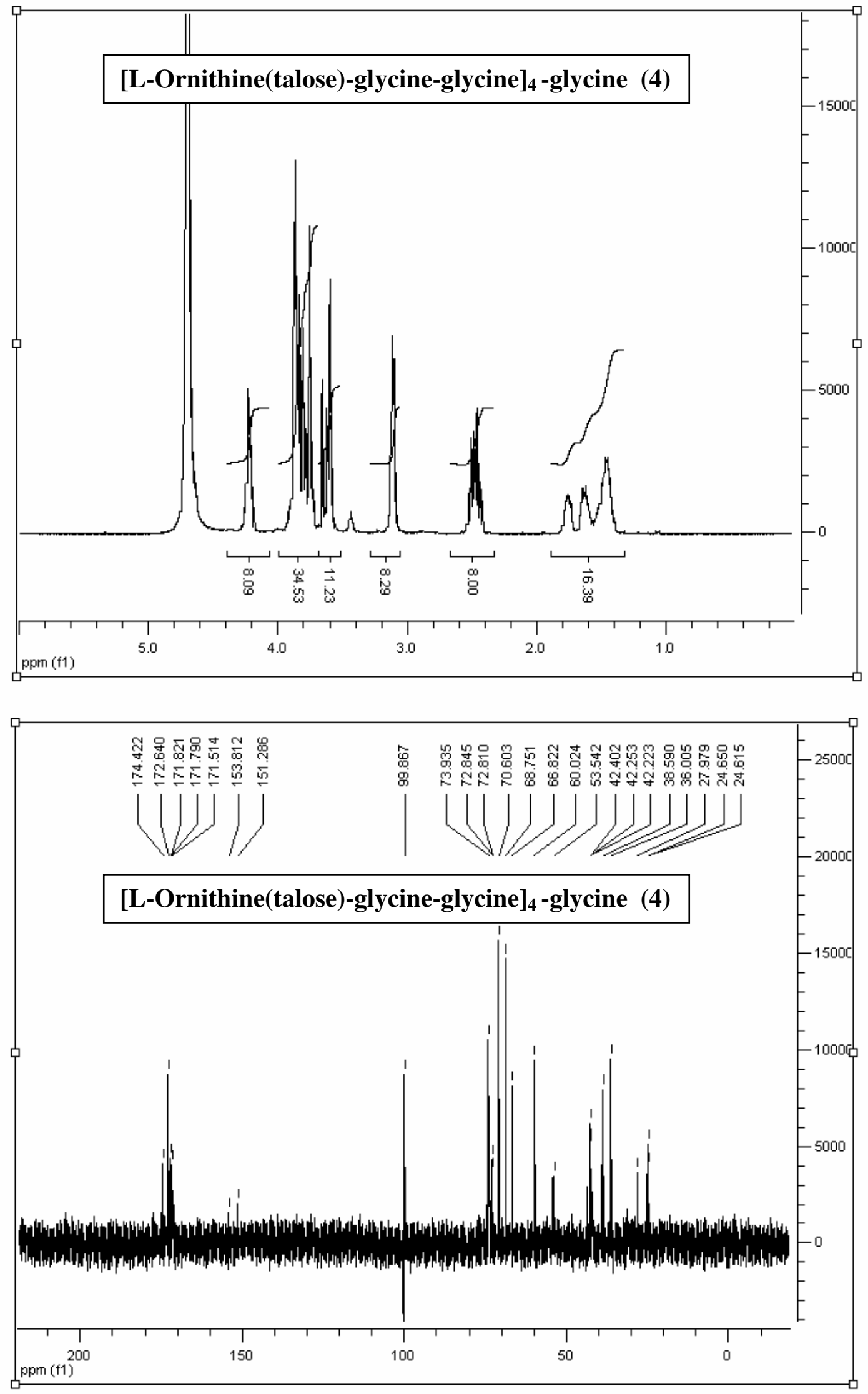